\title{
Ship Bow Force-Deformation Curves for Ship-Impact Demand of Bridges considering Effect of Pile-Cap Depth
}

\author{
Wei Fan ${ }^{1}$ and Wancheng Yuan ${ }^{2}$ \\ ${ }^{1}$ Department of Bridge Engineering, College of Civil Engineering, Hunan University, Changsha 410082, China \\ ${ }^{2}$ State Key Laboratory of Disaster Reduction in Civil Engineering, Tongji University, Shanghai 200092, China \\ Correspondence should be addressed to Wei Fan; wfan@hnu.edu.cn
}

Received 13 August 2013; Accepted 3 December 2013; Published 13 March 2014

Academic Editor: Vadim V. Silberschmidt

Copyright (C) 2014 W. Fan and W. Yuan. This is an open access article distributed under the Creative Commons Attribution License, which permits unrestricted use, distribution, and reproduction in any medium, provided the original work is properly cited.

\begin{abstract}
Since static analysis procedures in the vessel impact-resistant design codes neglect dynamic amplification effects related to bridge mass, ship-impact responses of bridges may be potentially underestimated. For this reason, several dynamic vessel-impact analysis techniques had been recently proposed, where a force-deformation curve was employed to model the vessel bow stiffness. Most of the recent works mainly focused on the force-deformation curves of the barge bows rather than the ship bows. In this paper, a highresolution finite element model is developed to obtain the ship bow force-deformation curves. The global and local characteristics of the ship bow force-deformation curves are discussed based on the finite element crush analyses between the ship bows and the rigid walls. Effect of pile-cap depth on the force-deformation curves (rather than only impact forces) is studied in detail, and the corresponding empirical equations are developed using an energy ratio method. Finally, a practical example of ship-bridge collision is investigated to validate the force-deformation curves considering the effect of pile-cap depth. It is found from the case study that the effect of pile-cap depth plays an important role in quantifying structural demand under impact loads. The case study also indicates that the developed equations are reasonable in practical applications.
\end{abstract}

\section{Introduction}

With the rapid growths in the numbers of merchant ships and bridges over navigable waterways, the frequency and severity of vessel-bridge collisions have markedly increased [1-3]. From 1951 to 2000 (over a 50-year period), 617 bridge failures in the United States were investigated by Harik et al. [4] and Wardhana and Hadipriono [5]. Out of the total reported failures, 29 (about 5\%) bridge failures were due to vessel collision, which was one of the most likely causes. In China, one of the recent catastrophic accidents is the collapse of the Jiujiang Bridge over the Xijiang River. It was hit by a fully loaded cargo ship (about 2000 tons) in June 2007, resulting in the loss of nine lives and the collapse of 200-meter bridge deck. In March 2008, the Jintang Bridge connecting Jintang Island to Ningbo was struck by an empty bulk carrier (about 10,000 DWT), causing 4 fatalities and the collapse of a 60-meter span. Therefore, the need is evident for bridges crossing navigable waterways to minimize their vulnerability to damage from vessel collisions.
Compared with well-established seismic and windresistant designs, vessel impact-resistant design of bridges is still in its infancy stages [3]. Currently, most of bridge design codes [3, 6-9] define an equivalent static load that bridge structures should be designed to resist. However, the dynamic amplification effects (e.g., inertial forces) are not taken into account in the static analysis procedure. As a result, the ship-impact demand of bridges may be potentially underestimated [10-13]. For this reason, several dynamic collision analysis methods were recently developed to consider the dynamic amplification effects, for example, coupled vessel impact analysis (CVIA) by Consolazio and Cowan [10], one-dimensional model for multibarge flotillas [14], and simplified interaction model for ship vessels $[15,16]$. When these dynamic methods are applied, a vessel forcedeformation curve needs to be determined beforehand in order to model vessel bow stiffness. The force-deformation curve relates the impact force $(P)$ to the vessel bow deformation (or crush depth $a$ ), which is denoted by $P$ - $a$ curve in this paper. The AASHTO provisions [3] prescribe a 


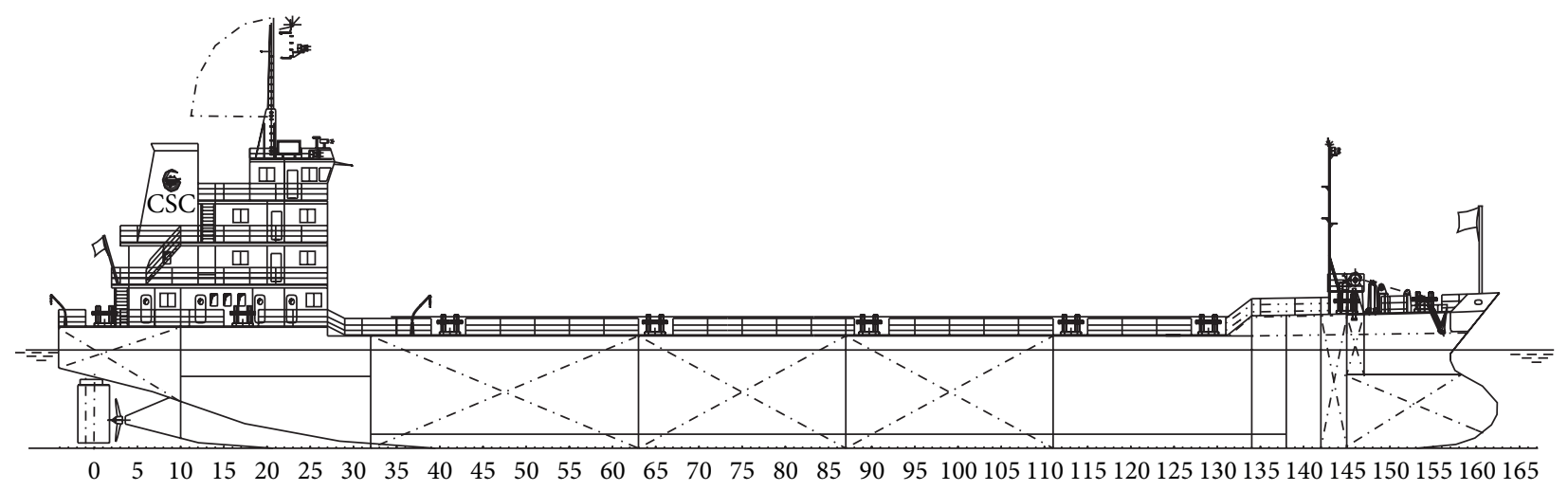

(a)

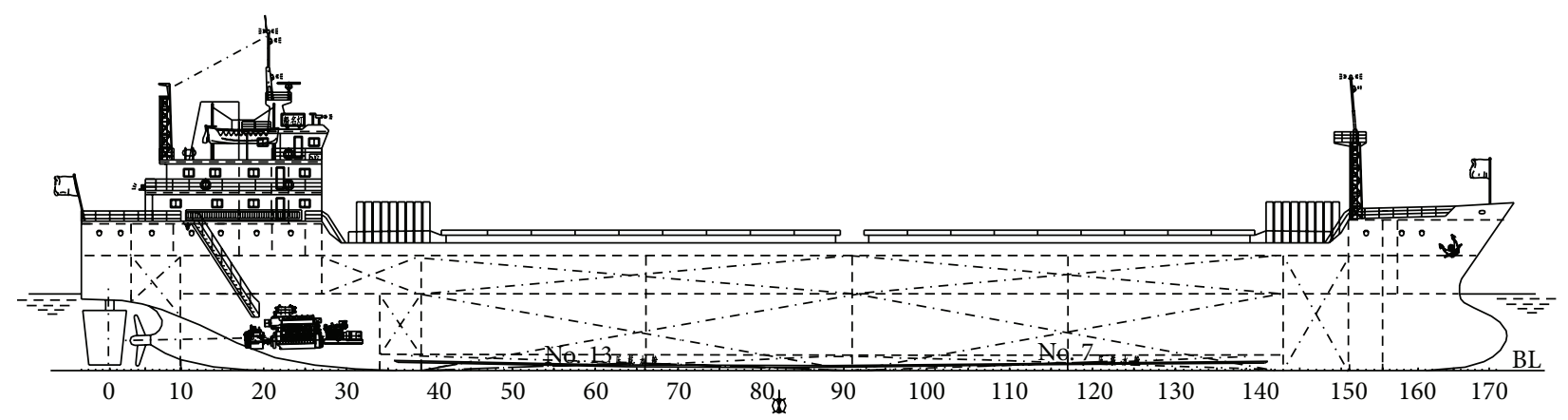

(b)

FIGURE 1: Schematic diagram of ships: (a) 5,000 DWT bulk carrier in Yangtze River; (b) 10,000 DWT river-sea container ship in the lower Yangtze River and offshore.

barge crush curve, which was determined from the experiments conducted by Meier-Dörnberg [17]. However, recent investigations [18-20] pointed out that the AASHTO forcedeformation relationship may be unreasonable, because the effects of the pier shape and size were not taken into account. An elastic perfectly plastic force-deformation relationship had been proposed to describe barge bow stiffness based on the finite element crush analyses of two common U.S. barges types by Consolazio et al. [21]. These previous studies mainly focused on the force-deformation relationships of the barge bows rather than the ship bows. In spite of similarity in some respects, there are a lot of differences between barges and ships, for example, bow shape and structure. Therefore, the characteristics of their force-deformation relationships may be profoundly different from each other.

In this paper, nonlinear finite element models of 5,000 DWT and 10,000 DWT ships that sail in China's navigable waterways are developed using the dynamic finite element analysis code LS-DYNA [22]. Firstly, the high-resolution finite element crush simulations are conducted to obtain the ship bow $P-a$ curves. The characteristics of these $P$ - $a$ curves are addressed in detail. Then, the effect of pile-cap depth on the $P-a$ curves (rather than only impact forces) is discussed for the two typical ship types, respectively. Using an energy ratio method, the empirical equations are proposed to account for the effect of pile-cap depth. Finally, the simplified interaction models using the developed $P$ - $a$ curves are validated by the high-resolution models of vessel-bridge collisions in a practical application.

\section{Characteristics of Ship Bow $P$-a Curve}

2.1. Ship Finite Element Model. The ship bow force-deformation curves ( $P$-a curves) can be readily determined from quasistatic tests through large-scale ship bow models [23, 24]. However, due to the high cost of construction, there are few such scale-model tests up to now, in particular, with an emphasis on evaluating vessel-impact demand of bridges [15]. Alternatively, the high-resolution finite element crush analyses are employed to obtain ship bow $P$ - $a$ curves, and then their characteristics are addressed.

Two typical ship types with different deadweight tonnages (DWTs) are studied in this paper. They have large frequency of passage compared to other medium and large vessels in China's inland waterways and are often selected as the design vessels in the bridges crossing Yangtze River, for example, the Huangshi Yangtze Highway Bridge, Tongling Yangtze Highway Bridge, the 4th Nanjing Bridge, and Sutong Bridge $[8,25]$. The first one is a 5,000 DWT bulk carrier with the twin-tail fin and bulbous bow shown in Figure 1(a), which usually sails in the middle and lower Yangtze River. The other is a 10,000 DWT river-sea container ship with the double bottom and bulbous bow (see Figure 1(b)), which usually sails in the lower Yangtze River and offshore of China. The basic parameters of these two ships are given in Table 1. 


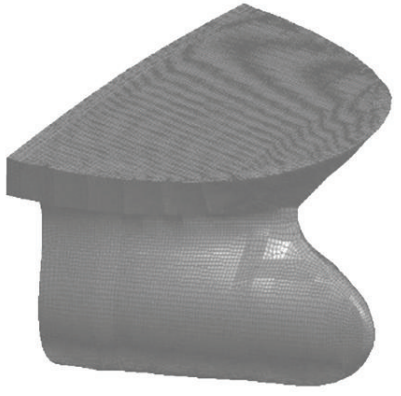

(a)

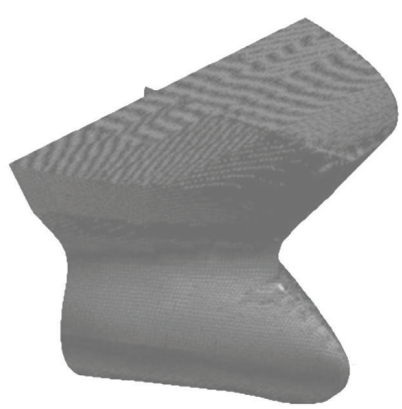

(c)

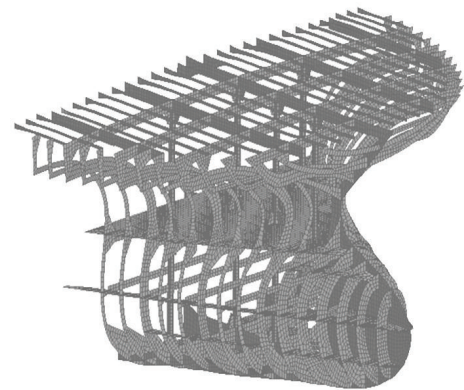

(b)

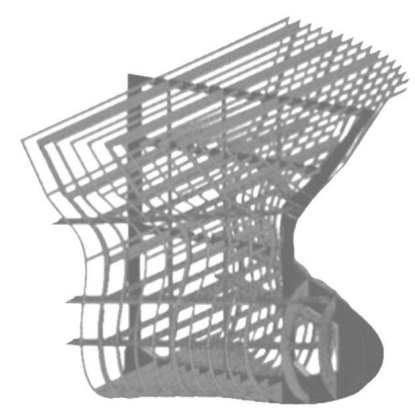

(d)

FIGURE 2: Finite element model of ship bows: (a) 5,000 DWT with outplate; (b) 5,000 DWT without outplate; (c) 10,000 DWT with outplate; (d) 10,000 DWT without outplate.

In order to obtain the $P$ - $a$ curves of the above two ships, the finite element models are generated using MSC. PATRAN and LS-PREPOST in this study. For modeling purposes, the ships are divided into two zones: the bow portion and the hull/stern portion. Similar to the previous studies $[18,20,26]$, the fine meshes are used to model ship bows in the models, as shown in Figure 2. Since ship kinetic energy is mainly dissipated through the bow deformation during a head-on collision, the hull/stern portion is simplified and modeled by coarse meshes to improve the computational efficiency.

In these two ship models, all ship portions are modeled using 4-node Hughes-Liu shell elements with reduced integration. The 5,000 DWT ship model contains 101,820 elements in total, where 57,781 elements are used to describe the bow portion (the mesh size is about $120 \mathrm{~mm}$ ). There are 86,991 elements in the 10,000 DWT ship model, which includes 70,761 in its bow portion (the mesh size is about $150 \mathrm{~mm}$ ). The elastic-plastic material model *MAT_PLASTIC_KINEMATIC (MAT_03), which is suited to model the isotropic and kinematic hardening plasticity with rate effects, is adopted in the crushing regions. It has been widely utilized to describe the mechanical behavior of structural steel under impact loads $[27,28]$. In order to reduce the analysis time, the rigid material model ${ }^{*}$ MAT_RIGID (MAT_20) is used to model the nonbow portions of vessel. All detailed parameters of the above material models are tabulated in Table 2.

2.2. Calibration of Numerical Model. The mesh size plays a critical role in the accuracy of the finite element models. It should be sufficiently small to capture the major local
TABLE 1: Basic parameters of the two ships.

\begin{tabular}{lcc}
\hline Parameter & 5,000 DWT & 10,000 DWT \\
\hline Length $(\mathrm{m})$ & 100.1 & 121.0 \\
Breadth (m) & 17.0 & 20.0 \\
Molded depth (m) & 6.4 & 9.0 \\
Design draft (m) & 5.0 & 6.0 \\
Displacement (ton) & 6878 & 11937 \\
\hline
\end{tabular}

deformations (e.g., folding and instability). On the other hand, the mesh size cannot be excessively small due to the constrains of the computational time and resources. Alsos and Amdahl [29] and Tornqvist and Simonsen [30] pointed out that when the element length-to-thickness ratio is within the range of 5 to 10 , the local stress and strain fields can be captured very well. For 5,000 DWT and 10,000 DWT ships in this paper, their element length-to-thickness ratios are approximately 8 to 10 in the bow meshes. Thus, these two ship finite element models meet the above requirements of mesh sizes. Furthermore, the mesh sizes of these ship bows are the same as the values in Sha and Hao [26]. Like the bargebridge collisions study [26], three different rigid wall mesh sizes $(50 \mathrm{~mm}, 100 \mathrm{~mm}$, and $200 \mathrm{~mm}$ in the crush models, as shown in Figure 3) are selected to perform mesh convergence tests. In the crush models, all ship-hull nodes are fixed in all degrees of freedom. The rigid walls with enough size are modeled by Hughes-Liu shell elements. For each rigid wall, a constant velocity is assigned to generate crushing at the ship bows along the longitudinal ship bow axis, as 
TABLE 2: Parameters of ship material models in numerical simulations.

\begin{tabular}{|c|c|c|c|}
\hline Component & LS-DYNA model & Input parameter & Magnitude \\
\hline \multirow{7}{*}{ Ship bow } & \multirow{7}{*}{${ }^{*}$ MAT_PLASTIC_KINEMATIC } & Mass density & $7.85 \times 10^{3} \mathrm{~kg} / \mathrm{m}^{3}$ \\
\hline & & Young's modulus & $2.06 \times 10^{5} \mathrm{MPa}$ \\
\hline & & Poisson’s ratio & 0.30 \\
\hline & & Yield stress & $235 \mathrm{MPa}$ \\
\hline & & SRC & $40.4 \mathrm{~s}^{-1}$ \\
\hline & & SRP & 5.0 \\
\hline & & Failure strain & 0.30 \\
\hline \multirow{3}{*}{ Ship hull } & \multirow{3}{*}{${ }^{*}$ MAT_RIGID $/{ }^{*}$ MAT_ELASTIC } & Mass density & Adjust \\
\hline & & Young's modulus & $2.06 \times 10^{5} \mathrm{MPa}$ \\
\hline & & Poisson’s ratio & 0.3 \\
\hline
\end{tabular}

Note. SRC and SRP are the strain rate parameters in Cowper-Symonds strain rate model [22]; the density of ship hulls should be adjusted according to ship loading conditions (e.g., ballasted, partial, and full load).

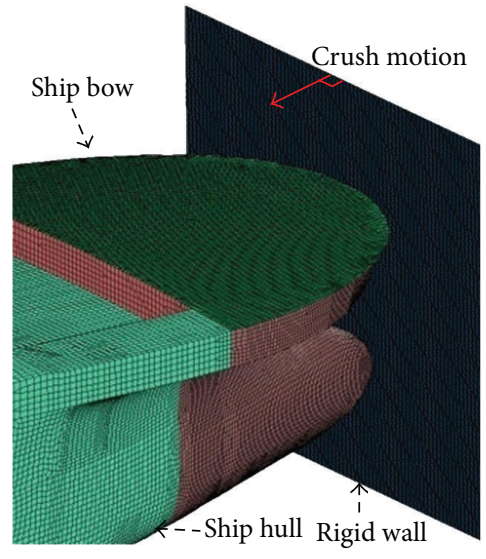

(a) $50 \mathrm{~mm}$

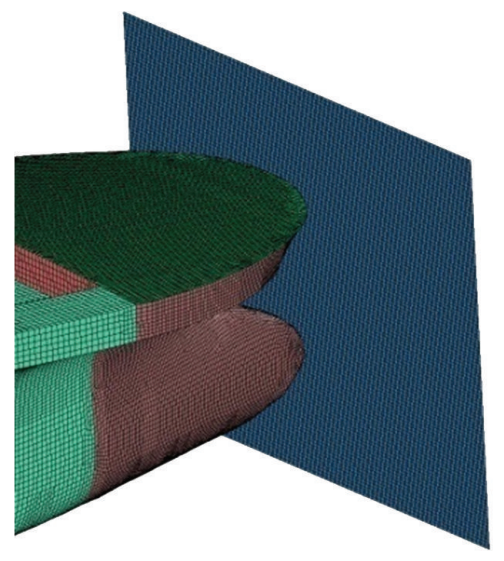

(b) $100 \mathrm{~mm}$

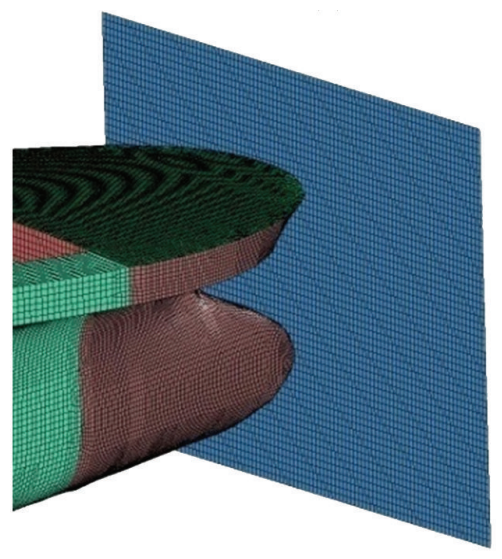

(c) $200 \mathrm{~mm}$

Figure 3: Crush analysis model with different mesh sizes of the rigid wall.

illustrated in Figure 3. A relatively larger speed $(5 \mathrm{~m} / \mathrm{s})$ is employed in the crush analysis to improve the computational efficiency. When the impact speed at a collision event is different from the crush speed, the speed influence on $P$ a curves is taken into account based on the proposed method in the previous studies $[16,28]$. The contact algorithm of *CONTACT_AUTOMATIC_SURFACE_TO_SURFACE in LS-DYNA is utilized to define the contact between the rigid wall and the ship bow. In addition, the contact algorithm of ${ }^{*}$ CONTACT_SINGLE_SURFACE is employed to simulate the internal contact after ship bow deforms.

The convergence test results in Figure 4 indicate that the models with three mesh sizes yield similar responses, including contact force and energy. Hence, $200 \mathrm{~mm}$ mesh is used in the rigid-wall finite element models to improve the computational efficiency of crush simulations. This is slightly different from the result in Sha and Hao [26]. Due to the existence of the contact corners (Figure 4 in Sha and Hao [26]), the barge finite element models are more sensitive to mesh sizes than the ship models, where the contact areas gradually increase (see Figure 3). In addition, LSTC [22] suggested that the part with finer mesh should be selected as the slave part in the numerical analyses. In other words, it may be acceptable that the mesh sizes of the master part (rigid wall) are larger than those of the slave one (ship bow).

In order to demonstrate the availability of * MAT_RIGID in the numerical models, a simple investigation is carried out using the crush models. As shown in Figure 5, when the elastic material model ( ${ }^{*}$ MAT_ELASTIC) is utilized for the vessel bows, the deformations of these two ship hulls increase with the ship bow crush depths. But their deformations are relatively small compared to the crush depths. These results are consistent with the deduction in Consolazio and Cowan [18] - no significant deformations occurred in the hopper section during bow crushing. Herein, the impact force from the model using * MAT_ELASTIC is defined as $x$, while the result for the model with *MAT_RIGID is set as $y$. When $y$ approximately is equal to $x$, it is implied that the coefficient of determination $\left(R^{2}\right)$ is close to 1.0 , where $R^{2}$ can be defined by

$$
R^{2}=1-\frac{\mathrm{SSE}}{\mathrm{SST}}
$$

where SST $=\sum_{i=1}^{N}\left(y_{i}-\bar{y}\right)^{2}$, SSE $=\sum_{i=1}^{N}\left(\hat{y}_{i}-y_{i}\right)^{2} ; y_{i}$ is the observed value; $\widehat{y}_{i}$ is the predicted value; $\bar{y}$ is the mean value 
TABLE 3: Comparisons between the numerical results and empirical formulas.

\begin{tabular}{|c|c|c|c|c|c|c|c|}
\hline \multirow{2}{*}{ Ship and speed } & \multirow{2}{*}{ AASHTO } & \multirow{2}{*}{ JTG D60 } & \multirow{2}{*}{ TB10002.1 } & \multicolumn{4}{|c|}{ Numerical results } \\
\hline & & & & $\bar{P}$ & $70 \%$ fractile & $\bar{P}+50 \%$ & $\bar{P}-50 \%$ \\
\hline \multicolumn{8}{|l|}{$5000 \mathrm{DWT}$} \\
\hline $2 \mathrm{~m} / \mathrm{s}$ & 16.97 & $25.4 / 12.7^{*}$ & 7.04 & 12.87 & 14.30 & 19.31 & 6.44 \\
\hline $4 \mathrm{~m} / \mathrm{s}$ & 33.94 & 25.40 & 14.07 & 22.23 & 24.70 & 33.35 & 11.12 \\
\hline \multicolumn{8}{|l|}{$10000 \mathrm{DWT}$} \\
\hline $2 \mathrm{~m} / \mathrm{s}$ & 24.00 & $35.8 / 17.9^{*}$ & 9.27 & 14.56 & 16.18 & 21.84 & 7.28 \\
\hline $4 \mathrm{~m} / \mathrm{s}$ & 48.00 & 35.80 & 18.54 & 26.72 & 29.66 & 40.08 & 13.36 \\
\hline
\end{tabular}

Note. ${ }^{*}$ Similar to the linear effect of impact speed on impact force used in AASHTO [3], the half values of the impact force at $4 \mathrm{~m} / \mathrm{s}$ are calculated when the impact speed is $2 \mathrm{~m} / \mathrm{s}$ for JTG D60 [8].

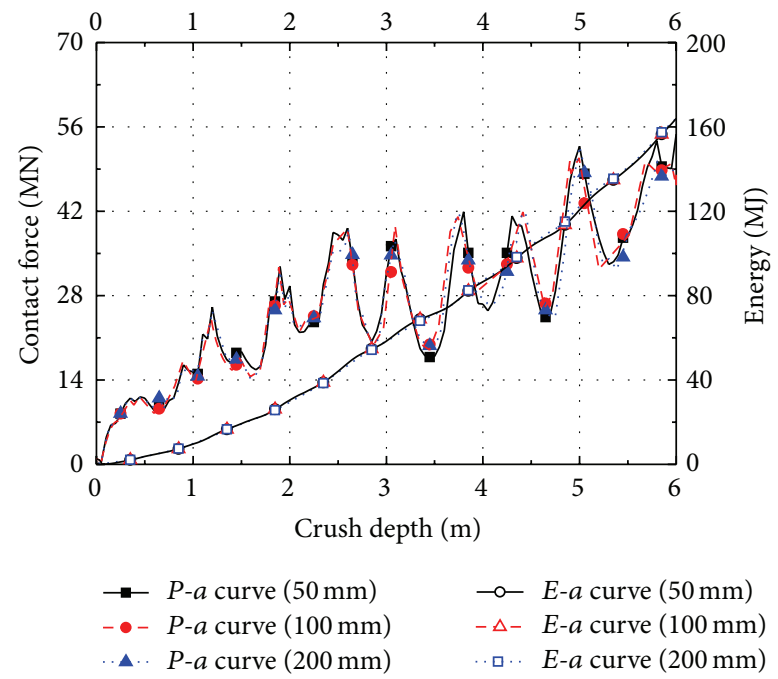

FIgURE 4: Comparison of the results for different mesh sizes.

of the observed results; $N$ is the number of observations. Figure 6 shows that the values of $R^{2}$ are close to 1.0 for these two ships. These imply that the differences between the models using ${ }^{*}$ MAT_ELASTIC and ${ }^{*}$ MAT_RIGID are not evident. Therefore, the use of *MAT_RIGID to model the nonbow portions is reasonable in practical applications.

Although some key issues in the ship finite element models have been addressed above, it is still necessary to verify the ship finite element models with the previous works or experimental results. As mentioned earlier, few experiments had been conducted involving vessel collisions, particularly, for China's ships. Limited test data was available for the validation of the vessel finite element models. For this reason, the empirical formulas in AASHTO [3] and China's bridge design codes (JTG D60 [8] and TB10002.1 [9]) are employed to calibrate the rationality of the above ship finite element models. The corresponding results are summarized in Table 3.

It was found from Woisin's ship collision tests that there was a \pm 50 percent scatter in the mean impact forces averaged over time $\left(\bar{P}_{t}\right)[3]$. Thus, besides the mean impact forces,

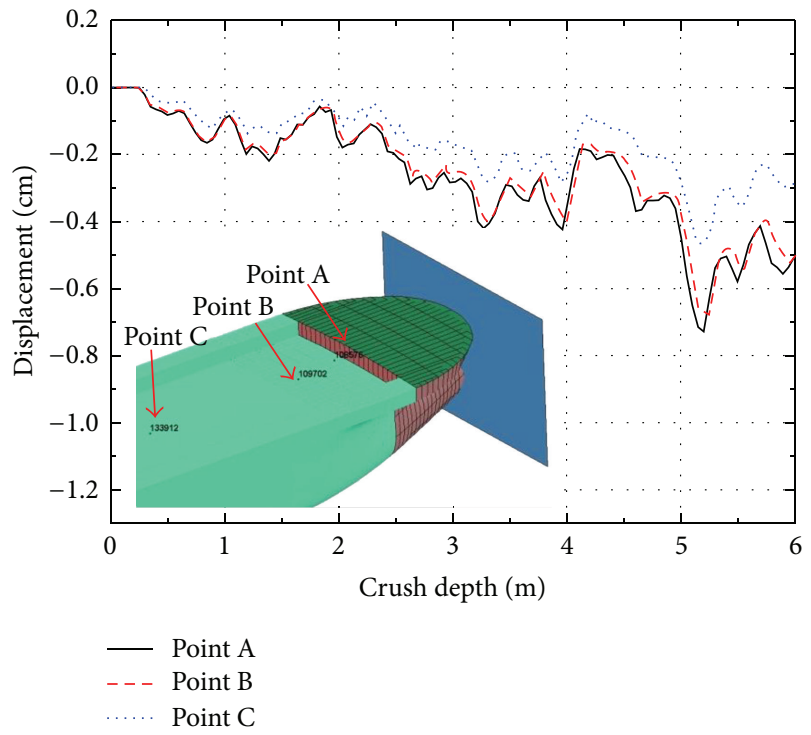

(a) 5,000 DWT

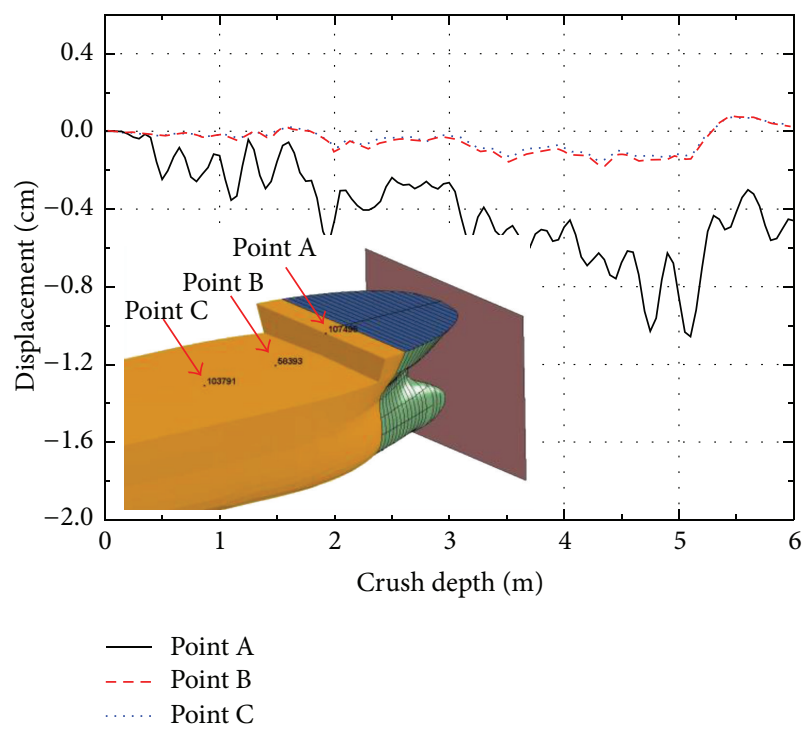

(b) $10,000 \mathrm{DWT}$

FIGURE 5: Displacement of the elastic ship hulls in the crush analyses. 


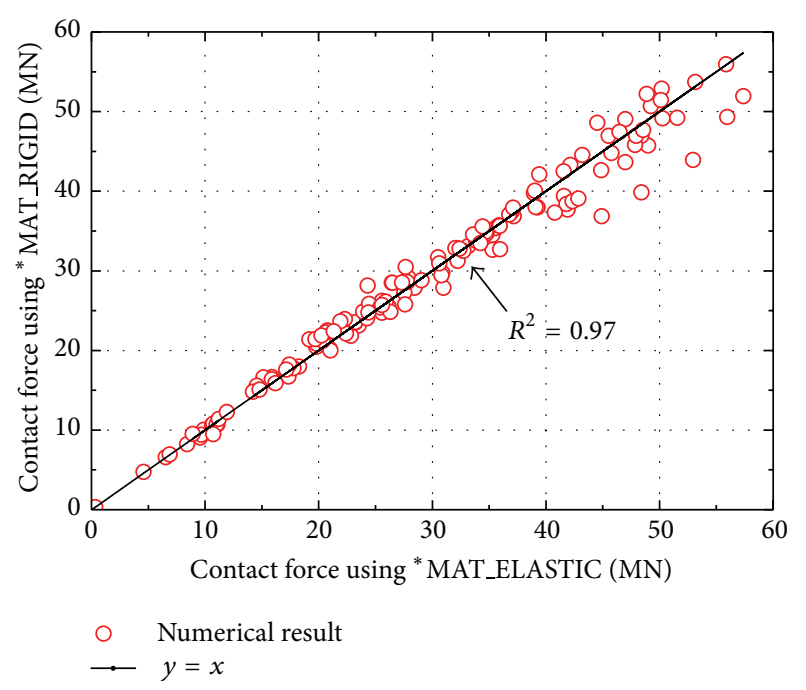

(a)

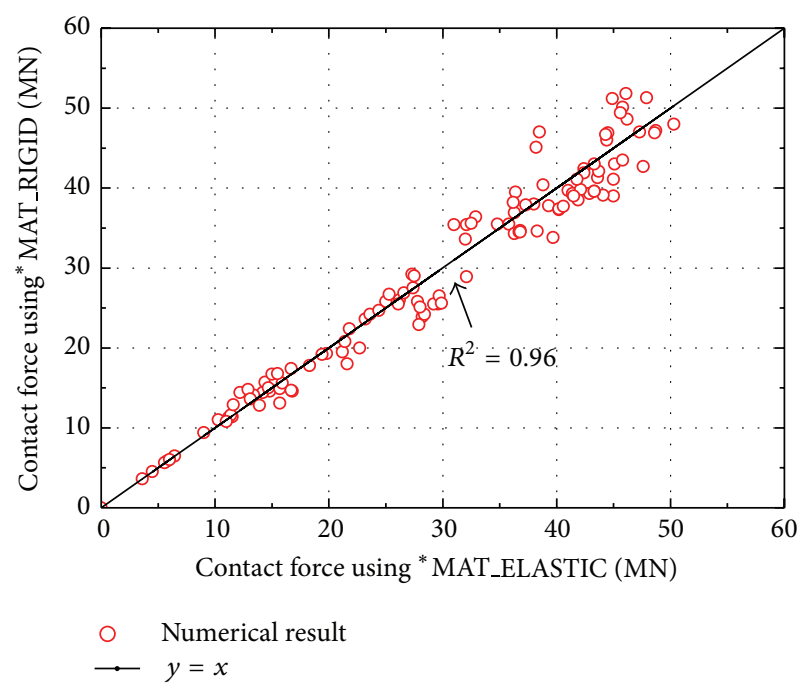

(b)

FIgURE 6: Comparison of contact forces using different material models in the nonbow vessel portions: (a) 5,000 DWT; (b) 10,000 DWT.

the results of $\bar{P}_{t} \pm 50 \%$ are calculated to present a reasonable range of ship impact forces. Similar to the AASHTO provision [3], the $70 \%$ fractile used for the design impact force (about 11\% increase in the mean force) is also given. Table 3 shows that the ship impact forces obtained from JTG D60 and TB10002.1 lie in the range of the numerical results. A good agreement is observed between the $70 \%$ fractile forces from the numerical analyses and the JTG D60 results for all of the impact cases. These results prove the reliability of the ship finite element models in evaluating the ship impact forces. Similar to the results from China's bridge design codes (JTG D60 and TB10002.1), the ship impact forces are also less than the results based on AASHTO's equation, namely, $P_{s}=1.2 \times 10^{5} V * D W T^{1 / 2}$, where $V$ is the impact speed. This is because different countries have different ship-building standards. As a result, the strength

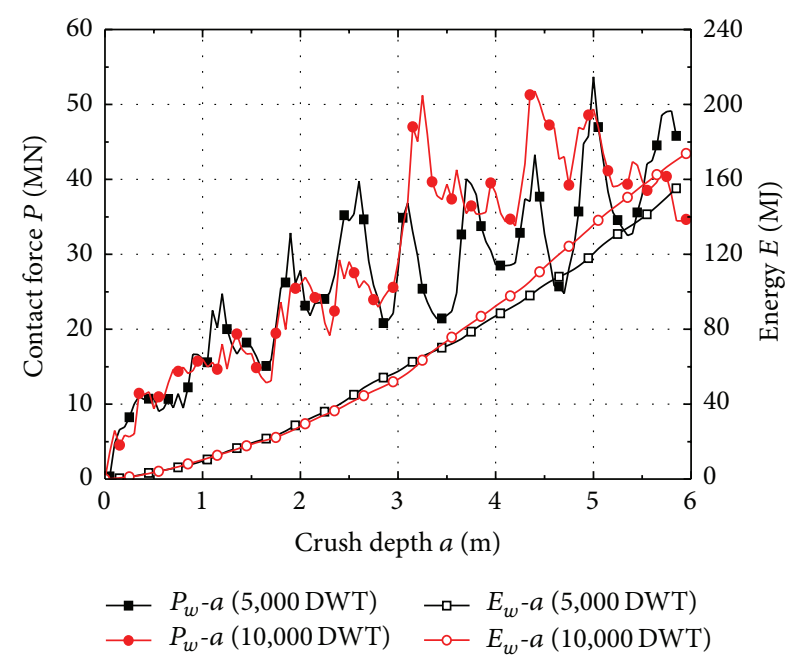

Figure 7: $P$ - $a$ curve versus $E_{w}-a$ curve of ship bows.

(resistance) of ship bows may be various due to the differences of the structural type, shape of the ship bow, and mechanical behaviors of ship steel. Additionally, AASHTO's equation was developed based on Woisin's collision tests. Nonetheless, Woision's limitations on size of vessel, type of vessel, and a minimum impact speed of 8 knots were not imposed. When ship impact forces are estimated for vessels smaller than 40,000 DWT, speeds less than 8 knots, and vessels other than bulk carrier, AASHTO [3], recommended that the extrapolation of this equation should be used until future research results are available. The impact loads determined from TB10002.1 $\left(P=\gamma * V * \sin \alpha\left[W /\left(C_{1}+C_{2}\right)\right]^{1 / 2}\right.$, where $\gamma$ is the reduction coefficient of the kinetic energy; $\alpha$ is the impact angle; $W$ is the ship weight; $C_{1}, C_{2}$ are the deformation coefficients of the vessel and pier, resp.), are less than the numerical results. These results are consistent with the observations in the previous studies [3, 31]. This is due to the fact that the suggested reduction coefficient of kinetic energy $(\gamma=0.3)$ in TB10002.1 is excessively small to underestimate the ship impact forces.

2.3. Global Characteristics of P-a Curve. As mentioned earlier, the ship bow $P$ - $a$ curves can be used to represent the ship bow stiffness during a quasistatic crush or head-on collision. Once the basic $P$ - $a$ curves are obtained from general-purpose contact-impact finite element analyses, they can be saved and subsequently retrieved for use. In particular, they can be employed in the simplified (macro-) model to estimate the dynamic demand of bridges subjected to vessel collisions $[10,15]$. Here, the characteristics of $P$ - $a$ curves will be firstly addressed in detail.

Using the above crush models, the $P-a$ and $E_{w}-a$ curves of these two ships (see Figure 7) are determined from crush simulations, where $E_{w}$ can be defined as

$$
E_{w}(a)=\int_{0}^{a} P(a) d a .
$$




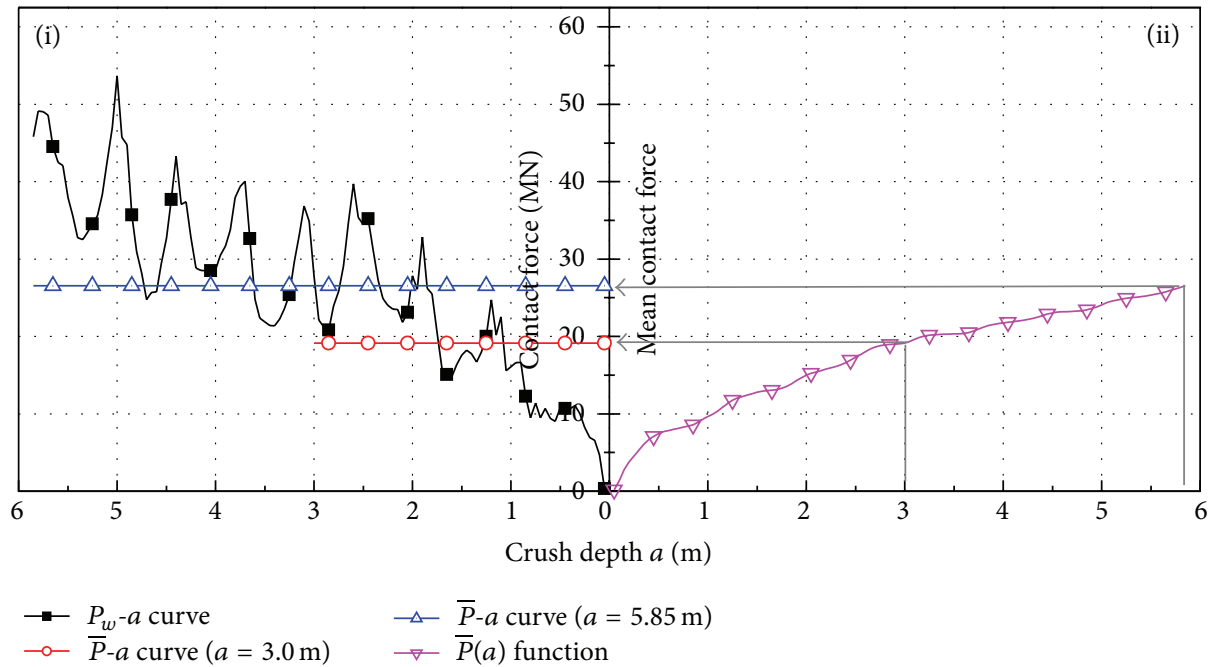

(a)

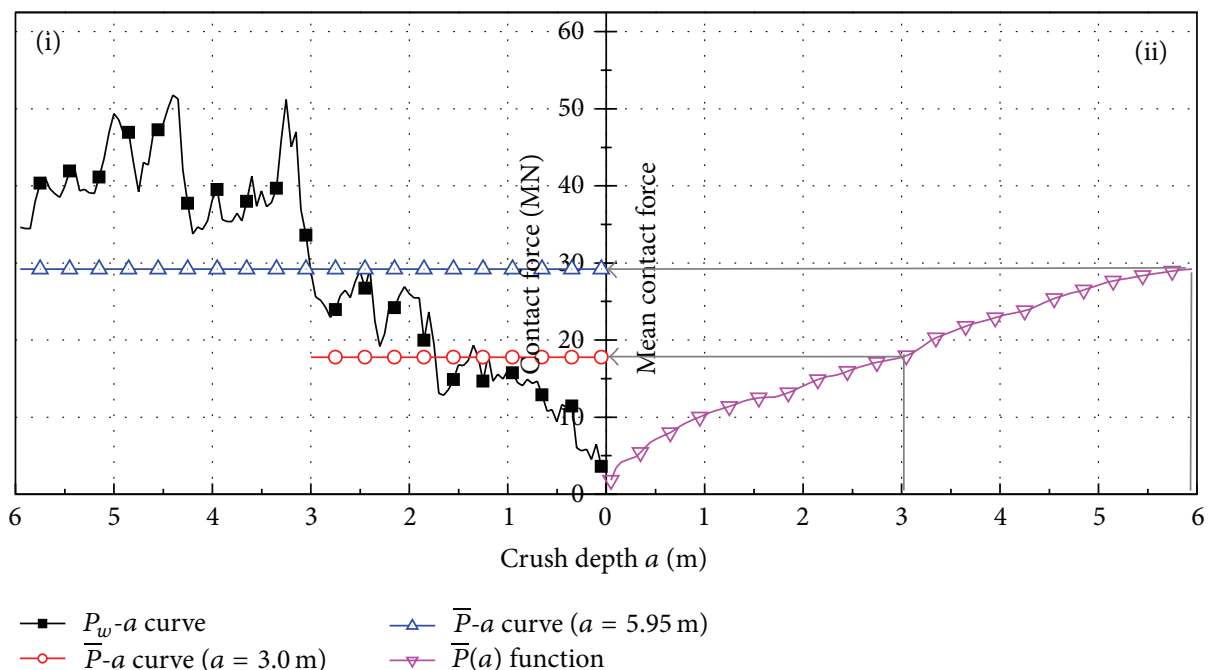

(b)

FIGURE 8: Mean contact force averaged over the damage depth: (a) 5,000 DWT; (b) 10,000 DWT.

In Figure 7, there are no obvious differences between 5,000 DWT and 10,000 DWT ships for both the $P$ - $a$ and $E_{p^{-}}$ $a$ curves, especially when the ship bow deformation is less than $4 \mathrm{~m}(a<4 \mathrm{~m})$. As observed in the experiment and theoretical analyses $[7,23,24,32]$, the contact force $P$ (ship bow resistance) can be given as

$$
\begin{gathered}
P=f\left(A, \sigma_{y}, n_{T}, n_{X}, n_{L}, \ldots\right) \\
\frac{\partial P}{\partial A} \geq 0, \quad \frac{\partial P}{\partial \sigma_{y}} \geq 0, \quad \frac{\partial P}{\partial n_{T}} \geq 0, \\
\frac{\partial P}{\partial n_{X}} \geq 0, \quad \frac{\partial P}{\partial n_{L}} \geq 0, \ldots,
\end{gathered}
$$

where $A$ is the cross-sectional area of deformed steel material; $\sigma_{y}$ is the yield stress of ship bow steel; $n_{T}$ is the number of $T$ sections in the cross section; $n_{X}$ is the number of $X$-sections in the cross section; $n_{L}$ is the number of $L$-sections in the cross section. Although the molded breadth and depth of 10,000 DWT ship are larger than those of 5,000 DWT ship (Table 1), the numbers of the structural elements (e.g., $T, X$, and $L$-sections) in the 10,000 DWT ship bow are not more than those of 5,000 DWT ship bow as shown in Figure 2. According to (3), it may be reasonable that the contact forces of 10,000 DWT ship are generally identical to the results of 5,000 DWT ship. It was found from Woisin's tests [3] that the contact force was profoundly affected by the shape and structure of vessel bows. Hence, these results also agree with the conclusions of Woisin's tests. The mean contact force $(\bar{P})$ averaged over the damage depth can be defined as

$$
\bar{P}(a)=\frac{1}{a} E_{w}(a)=\frac{1}{a} \int_{0}^{a} P(a) d a .
$$

Based on (4) and the results in Figure 7, the mean contact forces averaged over the crush depth $(\bar{P})$ are calculated for 5,000 DWT and 10,000 DWT ships, as shown in Figure 8. 


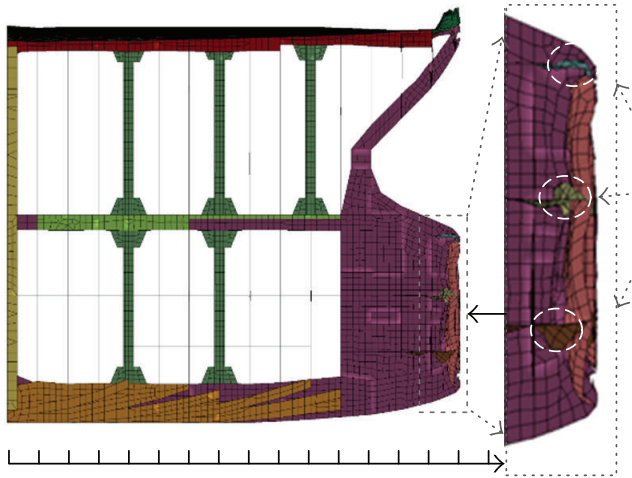

(a) Crush depth $a=1.6 \mathrm{~m}$

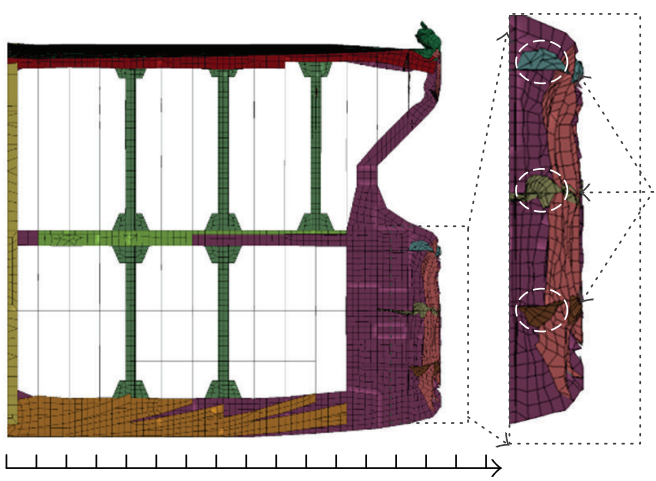

(c) Crush depth $a=2.1 \mathrm{~m}$

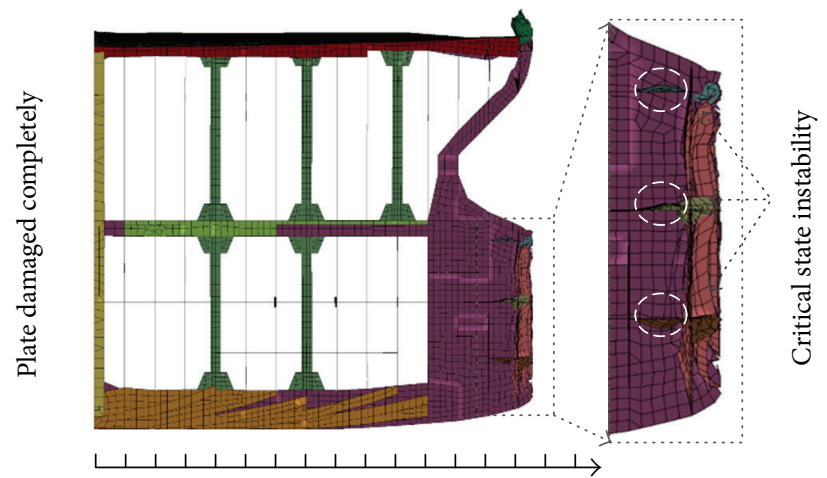

(b) Crush depth $a=1.9 \mathrm{~m}$

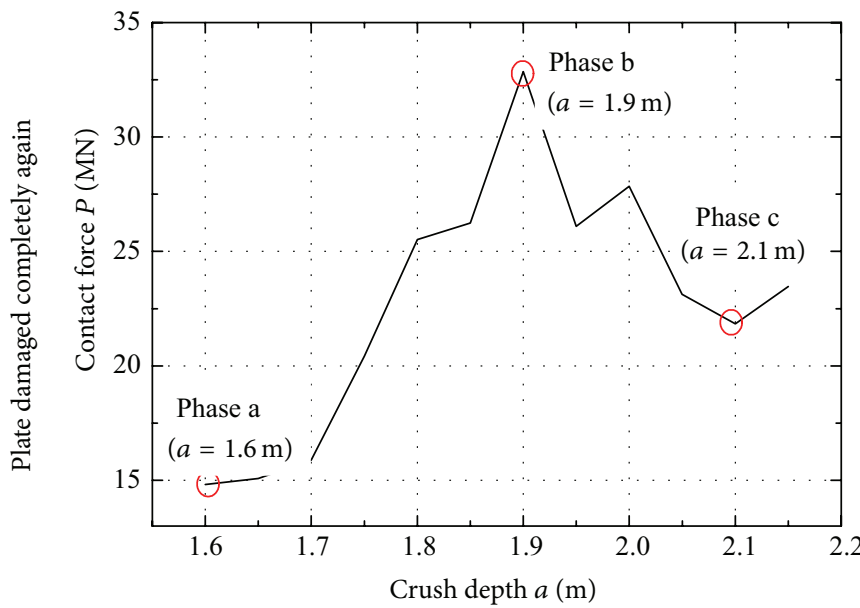

(d) $P$ - $a$ curve over the local crush depth

Figure 9: Local characteristics of $P$ - $a$ curves.

The mean forces acting on the rigid walls are shown to monotonically increase as the crush depths increase. It is apparent that, with the increase of crush depth, the contact areas between the rigid wall and the ship bow become larger and the numbers of the structural elements (e.g., $T, X$, and $L$-sections) also grow. Hence, it is observed that the mean contact forces $\bar{P}$ gradually rise based on (3). It should be noted that the $\bar{P}-a$ curve (see Figure 8 (left)) is different from the $\bar{P}(a)$ function shown in Figure 8 (right). The former means that, while $a \in\left(0, a_{1}\right)$, the contact force $(P)$ is a constant value $\bar{P}\left(a_{1}\right)$; but, for the $\bar{P}(a)$ function, $\bar{P}\left(a_{1}\right)$ is the mean contact force as the crush depth is only equal to $a_{1}$ (namely, $a=a_{1}$ ).

2.4. Local Characteristics of $P-a$ Curve. Figure 7 also presents that the local maximum and minimum contact forces occur regularly and alternately within the small range of crush depths. 5,000 DWT ship is taken as a typical example to address this phenomenon. When the horizontal plates over the previous slabs are completely damaged $(a=1.55 \mathrm{~m}$; see Figure 9(a)), the minimum force occurs (Figure 9(d)). Subsequently, due to the resistance associated with the next horizontal plates, the contact forces significantly increase so as to reach the critical state of plate instability and the local maximum contact forces $(a=1.84 \mathrm{~m}$; see
Figures 9(b) and 9(d)). With the increase of crush depths, the contact forces decrease until reaching the local minimum values again (Figures 9(c) and 9(d)).

In summary, the ship bow $P$ - $a$ curves have two basic characteristics compared with the barge bow force deformation curves [21]: (1) the mean contact forces gradually increase with crush depths due to the increases of the contact area and the numbers of the structural elements (e.g., $T, X$, and $L$-Sections); (2) the local maximum and minimum forces occur alternatively in the ship bow $P$ - $a$ curves because of the damage process of the horizontal plate from the beginning participation to completely failure.

\section{Effect of Pile-Cap Depth on P-a Curve}

3.1. 5,000 DWT Ship Bow. As mentioned above, the contact areas between the ship bow and the structure have a significant effect on the contact forces (or P-a curves). Obviously, the above contact areas between the ship bows and the rigid walls are different from the contact areas in the actual shipbridge collisions (i.e., contact between the ship bow and the pile cap). For this purpose, it is necessary to study the effect of pile-cap depth on $P$ - $a$ curves and ship-impact demands. 


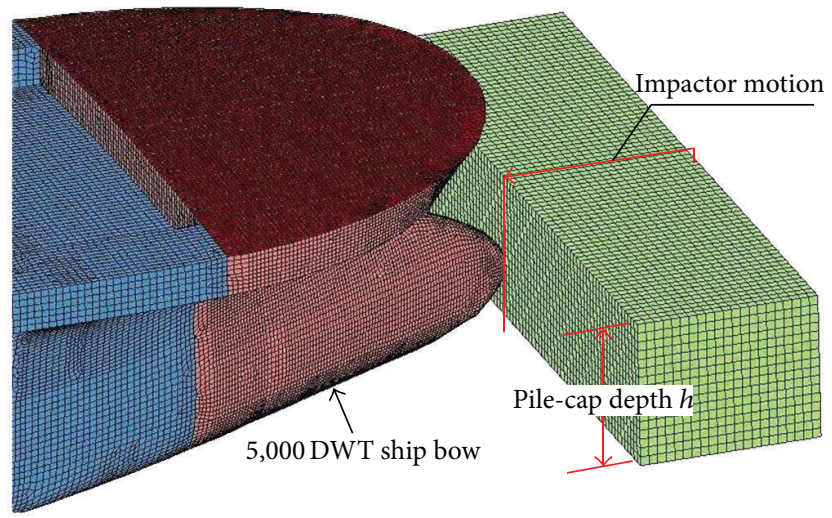

(a)

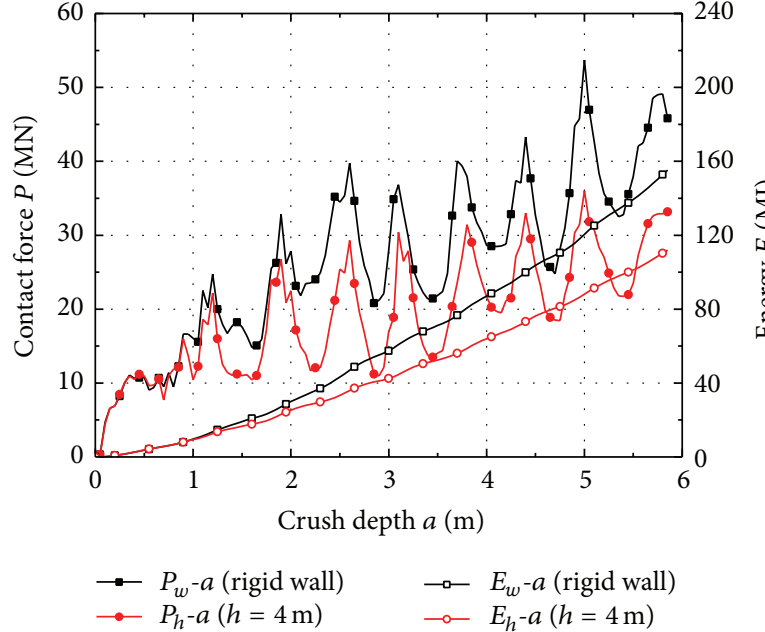

(b)

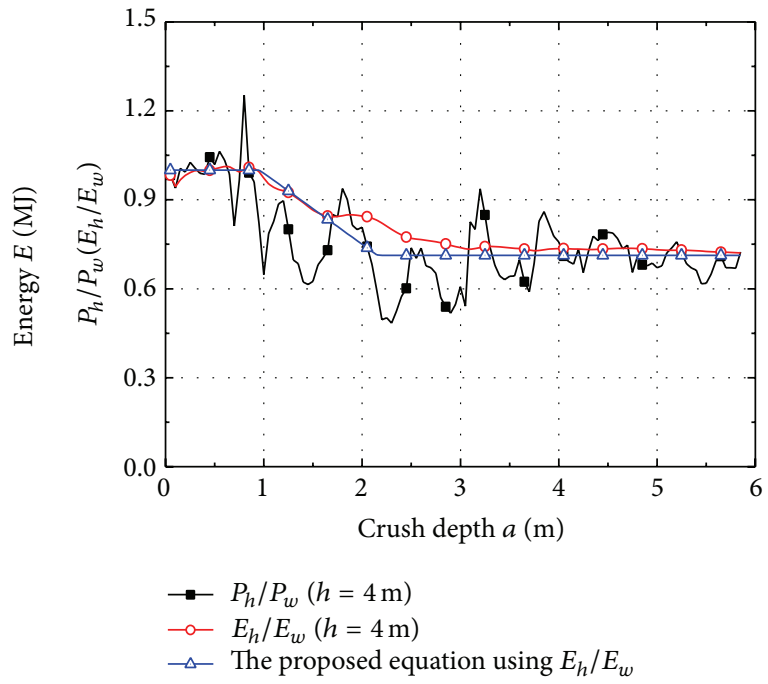

(c)

Figure 10: (a) 5,000 DWT crush model consisting of ship and pile cap; (b) $P$ - $a$ and $E$ - $a$ curves of rigid wall versus pile cap $(h=4 \mathrm{~m}$, $5,000 \mathrm{DWT}) ;(\mathrm{c}) P_{h} / P_{w}$ versus $E_{h} / E_{w}$ data $(5,000 \mathrm{DWT})$.

The finite element models of 5,000 DWT ship bow (Figure 10(a)) are developed to study the effect of pile-cap depth (depth $h: 3.0,4.0,5.0,6.0,6.5$, and $7.0 \mathrm{~m}$ ). It is shown in Figure 10(b) that the contact forces $(h=4 \mathrm{~m})$ are less than the results associated with the rigid walls due to the decrease of the contact areas, but both $P$ - $a$ curves have the similar trends. In addition, the effect of pile-cap depth on the contact force varies with continued bow deformation. For convenience, a factor $\left(\beta_{h}\right)$ is defined to quantify the effect of pile-cap depth as follows:

$$
\beta_{h}\left(\frac{h}{H}, a\right)=\frac{P_{h}(a)}{P_{w}(a)},
$$

where $H$ is the molded depth of ship bow and given in Table 1; $h / H$ is the ratio of the pile-cap depth to the molded depth; the $h$-subscript means the results associated with the pile cap at the depth of $h$ (e.g., $P_{h}$ is the contact force at the pile-cap depth of $h$ ); similarly, the $w$-subscript indicates the results associated with rigid walls. According to Figure 10(b) and $(5)$, the influence factors $\left(\beta_{h}\right)$ are calculated and presented in Figure 10(c). With the increase of crush depth, the factors $\left(\beta_{h}\right)$ gradually decrease and eventually trend to a steady value. Since the results using (5) are various at different crush depths, it may be difficult to determine $\beta_{h}$ from directly comparing $P_{w}$-a curves with $P_{h}-a$ curves. For this reason, an alternative approach is proposed to estimate the effect of pilecap depth. Based on (2) and (5), a relationship between the energy ratio $\left(E_{h} / E_{w}\right)$ and force ratio $\left(P_{h} / P_{w}\right)$ can be given as

$$
\frac{E_{h}(a)}{E_{w}(a)}=\frac{\int_{0}^{a} P_{h}(a) d a}{\int_{0}^{a} P_{w}(a) d a}=\frac{\int_{0}^{a} \beta_{h}(h / H, a) P_{w}(a) d a}{\int_{0}^{a} P_{w}(a) d a} .
$$

Taking the derivative of energy $(E)$ and force $(P)$ with respect to the crush depth (a) for (6),

$$
\beta_{h}\left(\frac{h}{H}, a\right)=\frac{E_{h}(a)}{E_{w}(a)}+\frac{d\left(E_{h}(a) / E_{w}(a)\right)}{d a} \frac{\int_{0}^{a} P_{w}(a) d a}{P_{w}(a)} .
$$

Owing to the second term in the right side of (7), $\beta_{h}$ defined in (5) is different from the energy ratio $E_{h} / E_{w}$. 


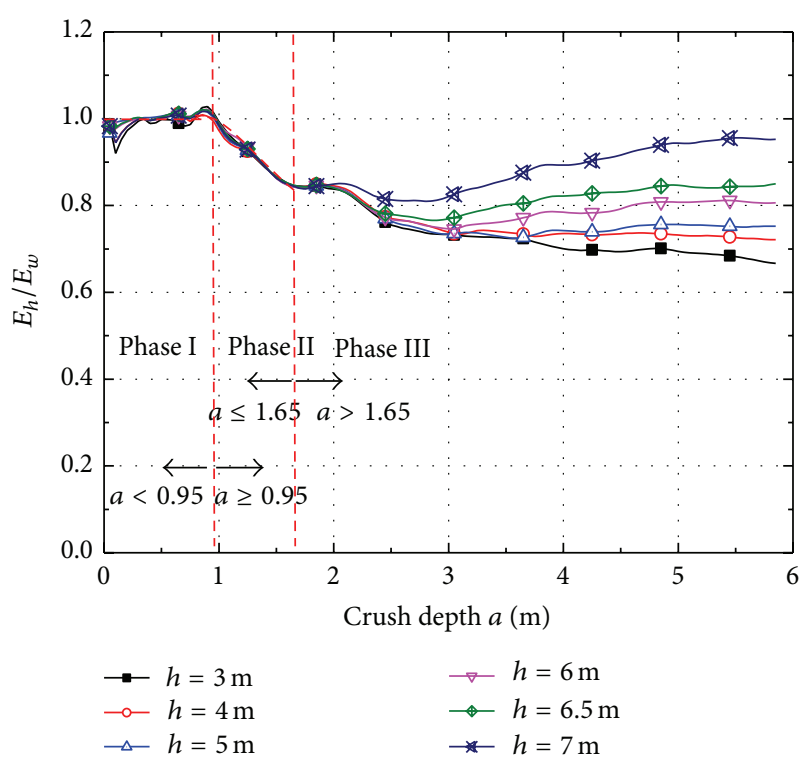

(a)

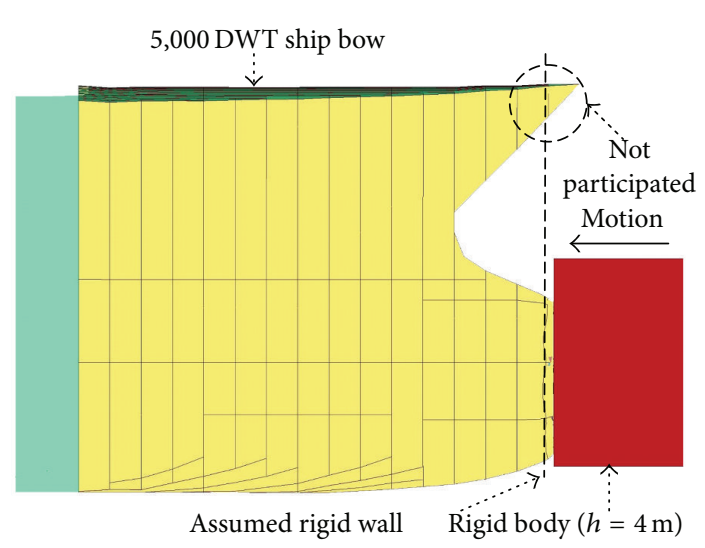

(c)

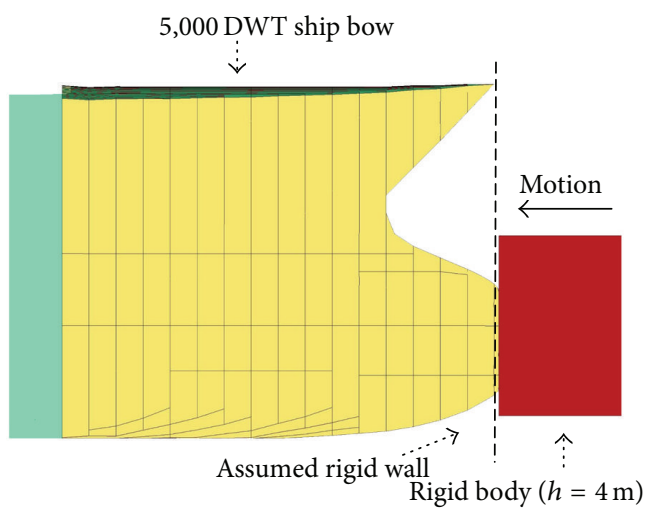

(b)

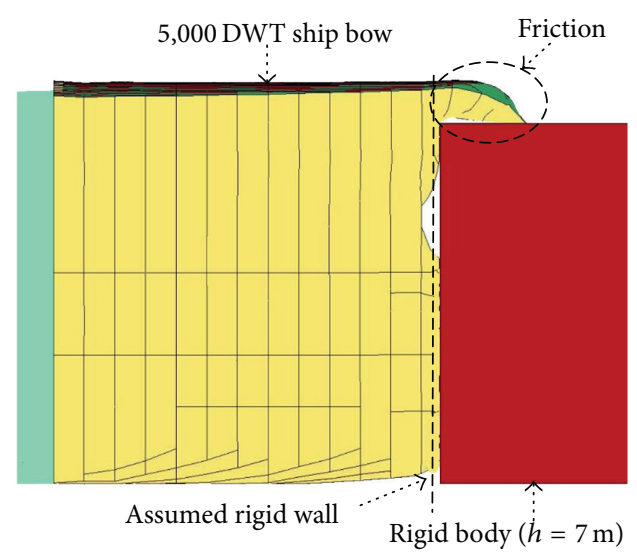

(d)

FIGURE 11: $E_{h} / E_{w}$ value and contact condition at different phases: (a) $E_{h} / E_{w}$ for all of pile-cap depths; (b) contact condition at Phase I; (c) contact condition at Phase II; (d) contact condition at Phase III.

Comparing the values of $P_{h} / P_{w}$ with $E_{h} / E_{w}$ (Figure 10(c)), the influence of the second term is not strongly pronounced. Thus, the impact energy curves ( $E_{h}-a$ and $E_{w}-a$ curves) are used to discuss the effect of pile-cap depth firstly, and then the influence of the second term in (7) will be evaluated.

Using the energy ratio $E_{h} / E_{w}$, the results of all different pile-cap depths are obtained and presented in Figure 11(a). It is observed that the $E_{h} / E_{w}$ results are almost equal to unity for all cases, provided that the crush depth is less than $0.95 \mathrm{~m}(a<0.95 \mathrm{~m})$. This may be attributed to the similar contact conditions of the pile caps and the rigid walls during ship bows crushing (see Figure 11(b)) when the crush depth is relatively small. This stage $(a<0.95 \mathrm{~m})$ is denoted by Phase I. Secondly, the contact conditions begin to have some differences between the rigid walls and the pile caps (Figure 11(c)) as the deformation level increases (i.e., $0.95 \mathrm{~m}<$ $a<1.65 \mathrm{~m}$ ). As a result, the $E_{h} / E_{w}$ results trend to linearly decrease for all pile-cap depths. Similarly, this stage $(0.95 \mathrm{~m}<$ $a<1.65 \mathrm{~m}$ ) is named as Phase II. When $a>1.65 \mathrm{~m}$, different pile-cap depths have various $E_{h} / E_{w}$, and the discrepancies among them significantly increase with the crush depth. Based on (3), this phenomenon can be reasonably addressed. This stage $(a>1.65 \mathrm{~m})$ is called Phase III. In addition, when the pile-cap depth is greater than or equal to $6.0 \mathrm{~m}$, the $E_{h} / E_{w}$ results increase with increasing crush depths at Phase III. This is primarily because there is a friction force between the upper pile-cap surfaces and the deformed ship bows (Figure 11(d)), when the pile-cap depth is large enough. The friction force becomes larger as the ship bow crush depths increase. Like the results of the barge force-deformation curves in $[18,20$, 21], ship bow force-deformation curves are also significantly influenced by the impacted surface geometry (i.e., flat and nonflat contact surfaces), when the crush depths are greater than a certain value (e.g., $a \geq 1.75 \mathrm{~m}$ in Figure 12). Hence, further investigation should be performed to quantify the influence of the impacted surface geometry on $P$ - $a$ curves in future. 


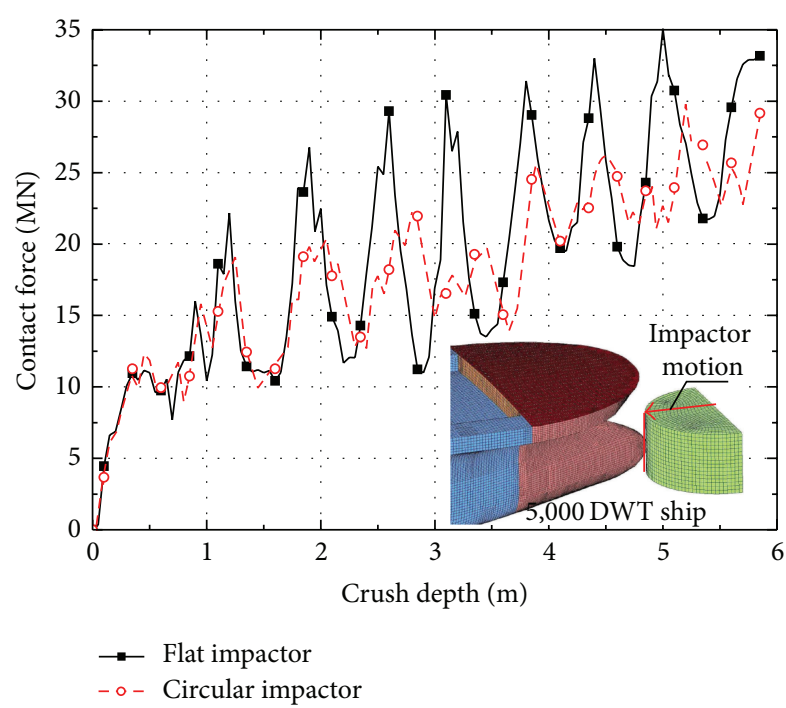

FIgURE 12: Comparison of $P$ - $a$ curves for different shape impactors. The numerical model of the flat impactor is shown in Figure 10(a) at the depth of $h=4.0 \mathrm{~m}$; the numerical model of circular impactor is presented in the above figure at $h=4.0 \mathrm{~m}$ and the diameter of $9.4 \mathrm{~m}$.

At Phase I $(0 \leq a<0.95 \mathrm{~m}), E_{h} / E_{w}$ can be assumed to be equal to unity for all pile-cap depths based on the above discussion. Substituting the $E_{h} / E_{w}$ values into (7),

$$
\begin{array}{r}
\beta_{h}\left(\frac{h}{H}, a\right)=1.0+\frac{d(1.0)}{d a} \frac{1}{P_{w}(a)} \int_{0}^{a} P_{w}(a) d a=1.0, \\
a \in[0,0.95) .
\end{array}
$$

At Phase II, a consistent linear trend is clearly identified and the trend lines can be fit through the data pairs (Figure 11(a)) of the energy ratio $\left(E_{h} / E_{w}\right)$ and the crush depth (a) using a least squares method (LSM). Two fitting equations (Figure 13(a)) are obtained under considering the boundary condition (BC: $E_{h} / E_{w}=1.0$ at $a=0.95 \mathrm{~m}$ ) or not. The coefficient of determination $\left(R^{2}\right)$ considering the boundary condition is close to 1.0 , and it is only slightly smaller than the result without the boundary condition. Therefore, considering the continuity at the point $\left(a=0.95 \mathrm{~m}, E_{h} / E_{w}=\right.$ 1.0 ), the equation for Phase II is given as

$$
\frac{E_{h}(a)}{E_{w}(a)}=1.23-0.24 a, \quad a \in[0.95,1.65] .
$$

Similarly, substituting (9) into (6), then

$$
\begin{aligned}
\beta_{h}\left(\frac{h}{H}, a\right)= & 1.23-0.24 a \\
-\frac{0.24}{P_{w}(a)} \int_{0}^{a} P_{w}(a) d a & \leq 1.23-0.24 a, \\
a & \in[0.95,1.65] .
\end{aligned}
$$

The inequality in (10) precisely agrees with the results shown in Figure 10(c); namely, $E_{h} / E_{w} \geq P_{h} / P_{w}$ at Phase II.

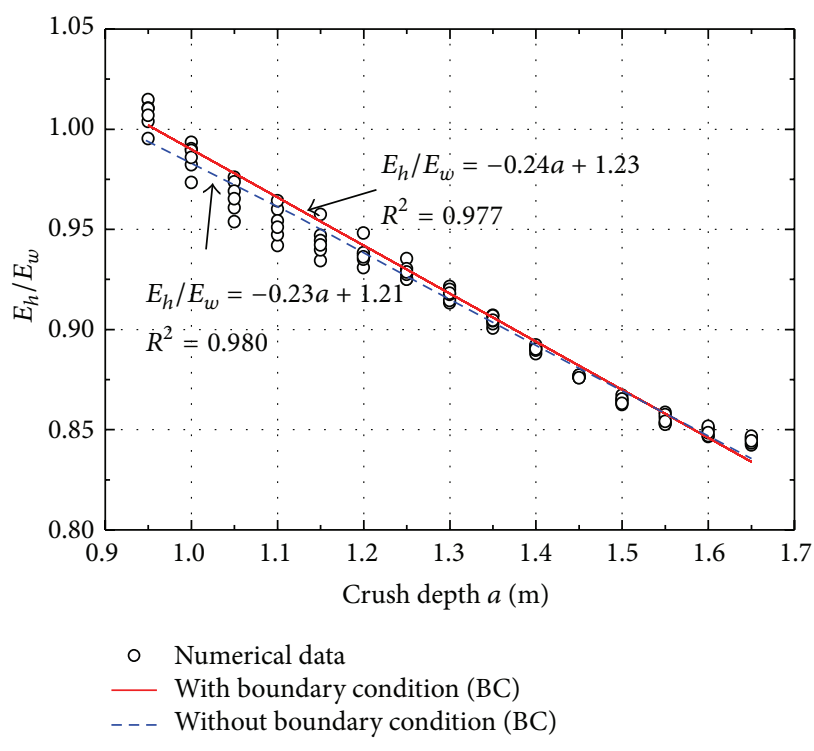

(a)

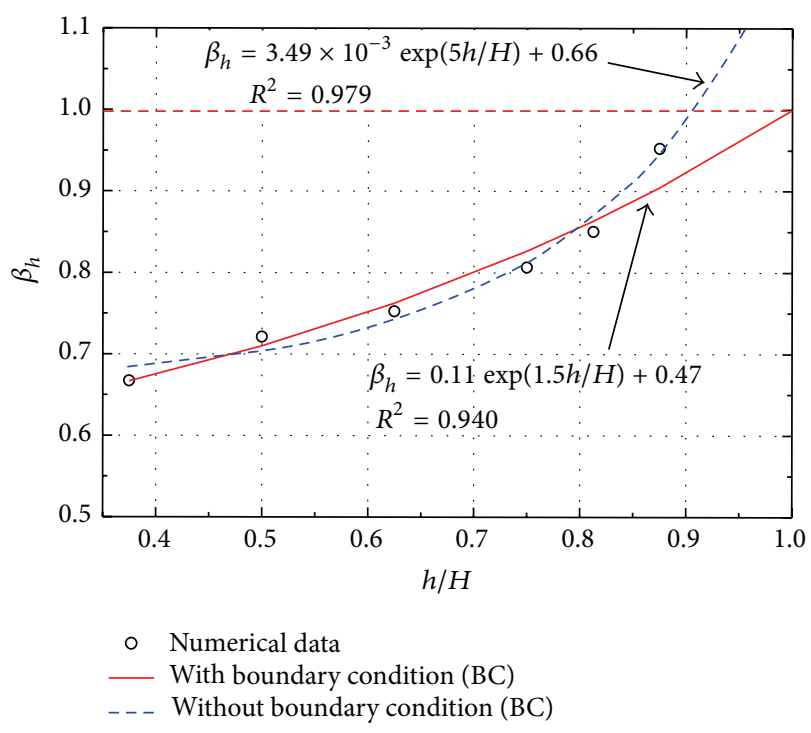

(b)

Figure 13: Phase analysis of 5,000 DWT ship bow: (a) Phase II; (b) Phase III.

However, solving the third term of (10) is too complicated to use in practical applications. In addition, the crush depth interval is very limit (i.e., $0.7 \mathrm{~m}$ ) at this phase. Hence, the third term in (10) can be ignored in the sense that the upper limit is utilized to determine $\beta_{h}$.

Compared with the previous two phases, the Phase III analyses are more complex due to the significant differences among various pile-cap depths and the participation of the friction forces between the pile-cap surfaces and the deformed ship bows. In general, when the $E_{h} / E_{w}$ results decrease with the increases of crush depths, the curve slopes (Figure 11(a)) are negative and the results of $\beta_{h}$ using (5) are less than $E_{h} / E_{w}$ (e.g., $h=3.0 \mathrm{~m}$ in Figure 11(a)). In contrast, the curve slopes (Figure 11(a)) are positive and the $\beta_{h}$ values 
are larger than $E_{h} / E_{w}$ (e.g., $\left.h=7.0 \mathrm{~m}\right)$. Hence, the $E_{h} / E_{w}$ values at the maximum crush depths are used to quantify the effect of pile-cap depth during this phase. The corresponding results are presented in Figure 13. The fitting equations with or without the boundary condition $\left(\beta_{h}=1.0\right.$ at $\left.h / H=1.0\right)$ can be obtained from these data points using LSM as follows:

$$
\begin{gathered}
\beta_{h}=3.49 \times 10^{-3} \exp \left(5.0 \frac{h}{H}\right)+0.66, \quad \text { without BC } \\
\beta_{h}=0.11 \exp \left(1.58 \frac{h}{H}\right)+0.47, \\
\text { with BC of }\left(\frac{h}{H}=1.0, \beta_{h}=1.0\right) .
\end{gathered}
$$

As shown in Figure 13, the coefficients of determination $\left(R^{2}\right)$ are slightly sensitive to the boundary condition in the fitting equations, but the boundary condition effect is not strongly pronounced. Considering the need of the physical meaning, the second equation is more reasonable and acceptable. Based on (8) to (11) and the continuity of (10) and (11), the following equations are concluded to estimate the effect of pile-cap depth for 5,000 DWT ship:

$$
\begin{aligned}
& \beta_{h}\left(\frac{h}{H}, a\right) \\
& = \begin{cases}1.0, & 0 \leq a<0.95 \\
1.23-0.24 a & \\
\geq 0.11 \exp \left(1.58 \frac{h}{H}\right)+0.47, & a \geq 0.95\end{cases}
\end{aligned}
$$

As observed in Figure 10(c), the results obtained from (12) are in good agreement with the numerical results. In other words, (12) is preliminarily validated for the estimation of the effect of pile-cap depth. When (12) is used in practices, it is necessary to choose a reasonable benchmark of $P$ - $a$ curve. When the benchmark curve is $P_{w}-a$ or $P_{h}$-a curve, the contact forces at the required pile-cap depth $\left(h_{x}\right)$ can be written as

$$
P\left(a, h=h_{x}\right)=\beta_{h_{x}}(a) P_{w}(a)=\frac{\beta_{h_{x}}(a) P\left(a, h=h_{0}\right)}{\beta_{h_{0}}(a)},
$$

where $h_{0}$ is the usual pile-cap depth in practices (e.g., $h_{0}=$ $4.0 \mathrm{~m}$ for 5,000 DWT ship). For each pile-cap depth, $R^{2}$ (as shown in Figure 14) are calculated under two different benchmark curves, respectively. Figure 14 indicates that, when $h \in$ [ $3 \mathrm{~m}, 6.5 \mathrm{~m}$ ], the results of $P_{h_{0}}-a$ curve are better than those of $P_{w}-a$ curve and can capture the local characteristics of $P$ - $a$ curves very well. As a result, the simplified model can reasonably estimate the demand of bridges subject to vessel collision when the $P_{h_{0}}-a$ curve is taken as the benchmark curve. When the pile-cap depth is very large, the $P$ - $a$ curve characteristics are closer to the force-deformation curves associated with rigid walls, such as when $h=7 \mathrm{~m}$ in Figure 14 . It should be noted that the relative errors between the $P_{w^{-}}$a and $P_{h_{0}}-a$ curves are less than $10 \%$ in most cases. Certainly, it is not very important to distinguish the differences between the $P_{w}-a$ and $P_{h_{0}}-a$ curves, especially at the conceptual or preliminary design stages of vessel-bridge collisions.
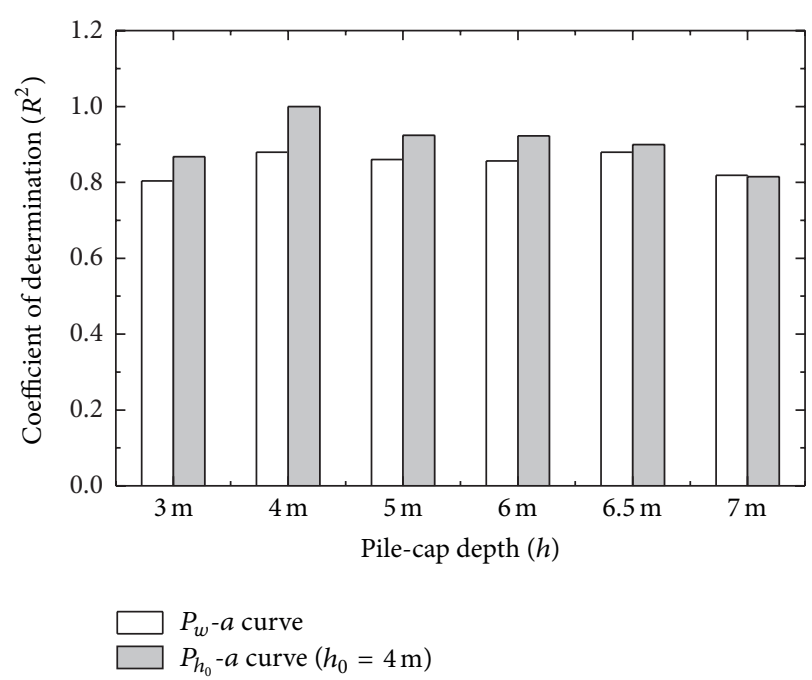

FIGURE 14: Correlation analysis of different benchmark curves (5,000 DWT).

3.2. 10,000 DWT Ship Bow. For 10,000 DWT ship bow, a similar finite element model (as shown in Figure 15(a)) is generated to study the effect of pile-cap depth on $P$ - $a$ curves and ship-impact demand of bridges. The trends of the results shown in Figure 15(b) are approximately the same as those of 5,000 DWT ship. The same method using the energy ratio $\left(E_{h} / E_{w}\right)$ is employed herein to address the effect of pilecap depth for 10,000 DWT ship bow in detail. Similar to the 5,000 DWT ship results, the effect of pile-cap depth can be divided into three different phases: Phase I with no reduction $\left(E_{h} / E_{w} \approx 1.0\right)$, Phase II with the same trends for all pile-cap depths, and Phase III with the variances at different pile-cap depths, respectively. This observation also implies that these three influenced phases are a common phenomenon, and the above method can be widely utilized to assess the effect of pile-cap depth on $P$ - $a$ curves for other ships. Because of the shape and structure differences between the two ships, the thresholds of various phases are different from the results of 5,000 DWT ship. Here, Phase I is the case when $a<0.3 \mathrm{~m}$, Phase II is for $0.3 \mathrm{~m} \leq a<0.85 \mathrm{~m}$, and Phase III is for $a \geq 0.85 \mathrm{~m}$.

At Phase I, there are no differences in the contact areas between the rigid walls (Figure 3(b)) and the pile caps (Figure 15(a)), and then (6) becomes

$$
\begin{array}{r}
\beta_{h}\left(\frac{h}{H}, a\right)=1.0+\frac{d(1.0)}{d a} \frac{1}{P_{w}(a)} \int_{0}^{a} P_{w}(a) d a=1.0, \\
a \in[0,0.3 \mathrm{~m}) .
\end{array}
$$

For each pile-cap depth in Figure 16, the $E_{h} / E_{w}$ values decrease with the increases of crush depth at Phase II. However, the trends are different from those of 5,000 DWT ship, and a linear relationship between $E_{h} / E_{w}$ and $a$ is not shown clearly. Hence, the nonlinear functions are employed to fit the data points at Phase II besides the linear functions. The analytical results are plotted in Figure 17, where the boundary condition is that $E_{h} / E_{w}=1.0$ at $a=0.3 \mathrm{~m}$. 


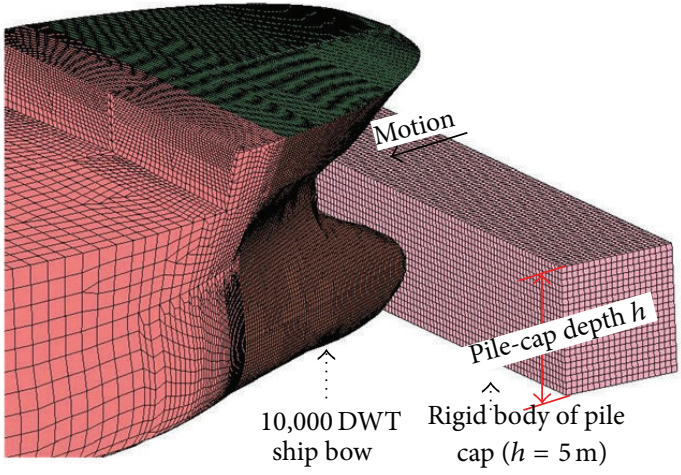

(a)

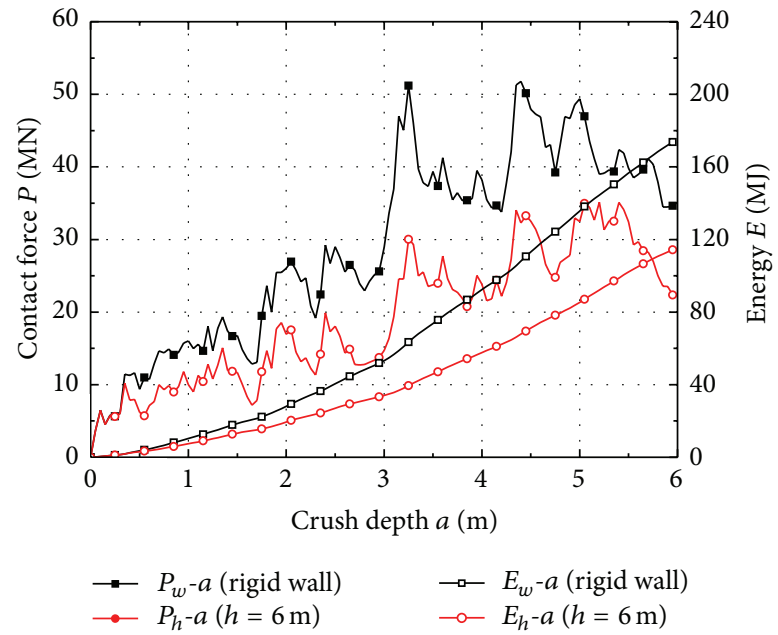

(b)

FIGURE 15: (a) Finite element model of ship collision with pile cap $(10,000 \mathrm{DWT})$; (b) $P$ - $a$ curve and $E$ - $a$ curve of rigid wall versus pile cap $(h=6 \mathrm{~m}, 10,000 \mathrm{DWT})$.

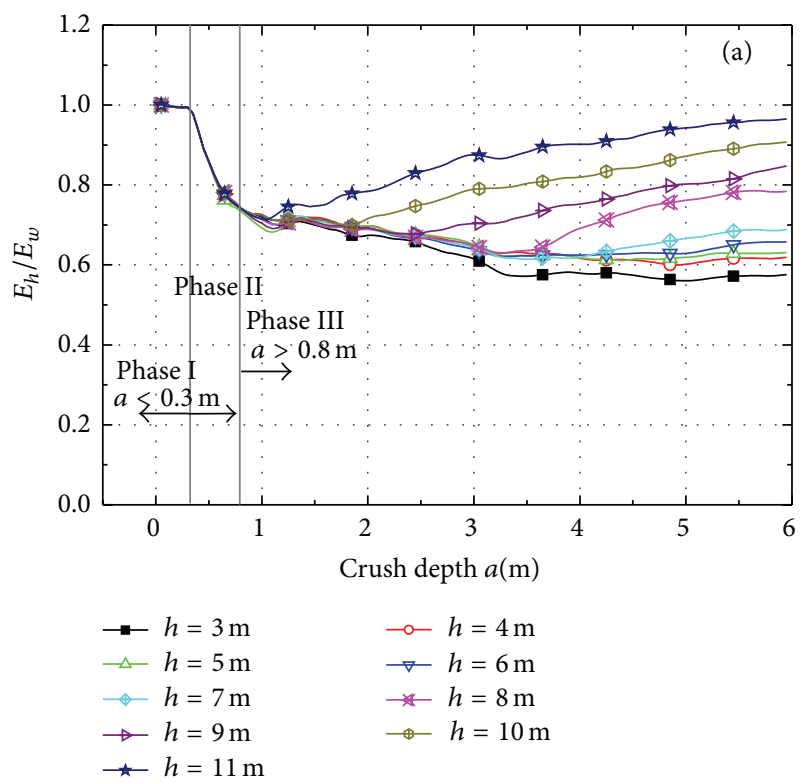

Figure 16: $E_{h} / E_{w}$ for different pile-cap depths (10,000 DWT).

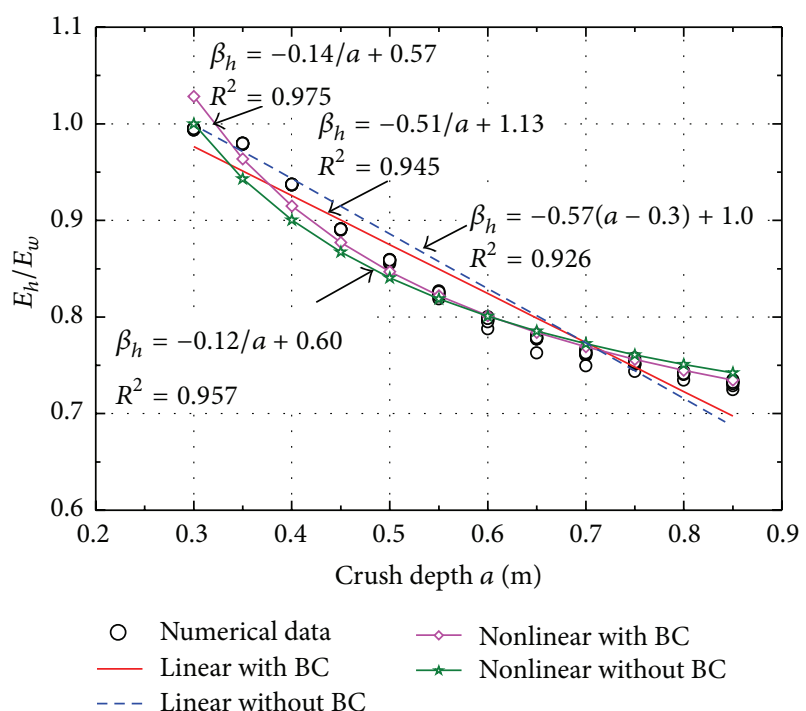

(a)

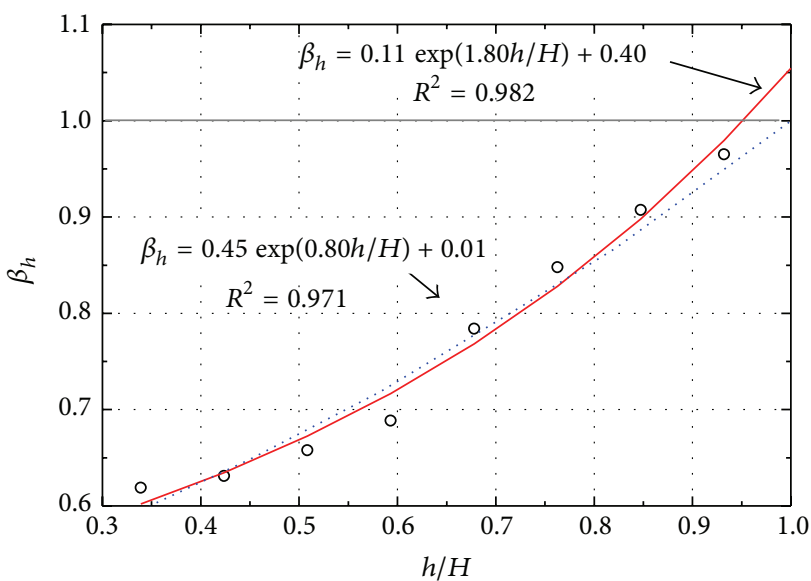

- Numerical data

- Without BC With BC

(b)

FIgURE 17: Phase analysis of 10,000 DWT ship bow: (a) Phase II; (b) Phase III.

Figure 17 indicates that these four fitting equations match the numerical results very well. The nonlinear fitting equations are slightly better than the linear ones. Since the process from the cases of $E_{h}(a) / E_{w}(a)$ to $\beta_{h}(h / H, a)$ in (6) is too complicated when the nonlinear function is employed, the upper limit of the linear function with the boundary condition is adopted to determine $\beta_{h}$, which is given as

$$
\begin{aligned}
\beta_{h}\left(\frac{h}{H}, a\right)= & 1.17-0.57 a \\
& -\frac{0.57}{P_{w}(a)} \int_{0}^{a} P_{w}(a) d a \leq 1.17-0.57 a
\end{aligned}
$$




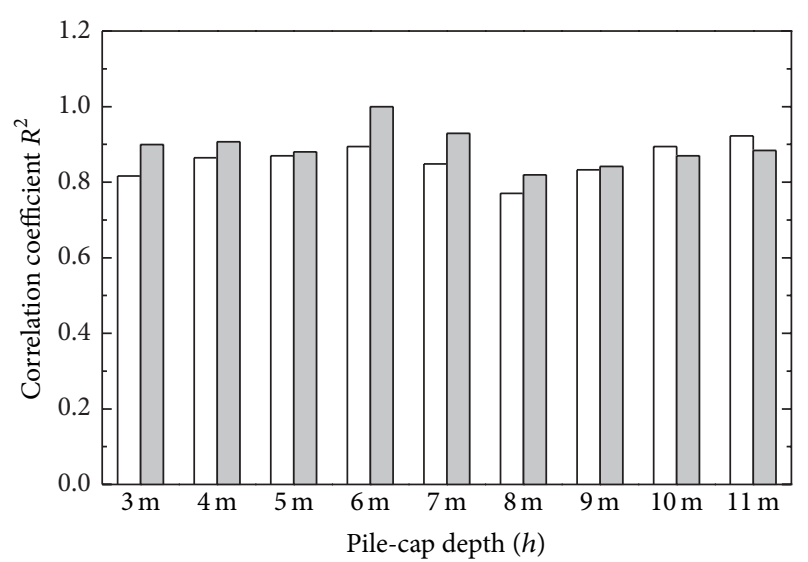

$P_{w}-a$ curve

$P_{h_{0}}-a$ curve $\left(h_{0}=6 \mathrm{~m}\right)$

Figure 18: Comparison of different benchmark curves $(10,000$ DWT).

Similarly, compared with the previous phases, the values of $E_{h} / E_{w}$ vary with the pile-cap depths as shown in Figure 17. Like 5,000 DWT ship, the values of $E_{h} / E_{w}$ at the maximum crush depth are utilized to describe the effect of pile-cap depth at Phase III. Using the least squares method, the factor $\beta_{h}(h / H, a)$ for the case $a>0.8 \mathrm{~m}$ is

$$
\begin{gathered}
\beta_{h}=0.11 \exp \left(1.80 \frac{h}{H}\right)+0.40, \quad \text { without BC } \\
\beta_{h}=0.45 \exp \left(0.80 \frac{h}{H}\right)+0.01,
\end{gathered}
$$

with the $\mathrm{BC}$ of $\left(\frac{h}{H}=1.0, \beta_{h}=1.0\right)$.

Figure 13(b) shows that the difference between these two formulas in (16) is very small. Thus, the second formula with the boundary condition was employed at Phase III. Based on (14) to (16) and the continuity at the boundary point, the factor $\beta_{h}(h / H, a)$ for all three phases can be written as

$$
\begin{aligned}
& \beta_{h}\left(\frac{h}{H}, a\right) \\
& = \begin{cases}1.0, & 0 \leq a<0.3 \\
1.17-0.57 a \geq 0.45 \exp \left(0.80 \frac{h}{H}\right)+0.01, & a \geq 0.3 .\end{cases}
\end{aligned}
$$

Based on (13) and (17), the P-a curves with the effect of pile-cap depth can be obtained, and the same correlation analyses are conducted to validate the above equations, as illustrated in Figure 14. Generally, most of the observations from Figure 14 are similar to the results for 5,000 DWT ship. As shown in Figure 18, the results using (17) are in good agreement with the numerical results from general-purposed contact-impact analyses, no matter which benchmark curves are used (the $R^{2}$ are 0.857 and 0.892 on average for $P_{w}-a$ and $P_{h_{0}}-a$ curves, resp.). When the pile-cap depth is relatively small, the performance of $P_{h_{0}}-a$ curve is better than that of $P_{w}-a$ curve. Conversely, taking the $P_{w^{-}} a$ curve as the benchmark is better.

In summary, the effect of pile-cap depth on $P$ - $a$ curves can be presented by three different phases for both ships: Phase I with no reduction $\left(E_{h} / E_{w} \approx 1.0\right)$, Phase II with the same trends for all cases, and Phase III with the variance at different pile-depth depths, respectively. Through the detailed discussion of these three phases, (12) and (17) are developed to account for the effect of pile-cap depth on the ship bow $P$-a curves, respectively. In theory, the above analytical procedure can be applied into other ships with different DWTs. If more ship finite element models and data are available, the effect of DWTs on $P$ - $a$ curves can be also discussed, which will be studied in future.

\section{Validation and Discussion}

4.1. Finite Element Model and Parameters. To further validate the above developed $P-a$ curves and equations (see (12) and (17)) considering the effect of pile-cap depth, a typical bridge crossing Yangtze River is selected as a practical example. The main bridge is a six-span continuous girder bridge with two approach spans of 102 meters and four internal spans of 185 meters. Since the ship impact load is a typical local action on bridges, it is assumed that the influence of the approach bridge far away from the navigable channels is ignored. The section of the steel box girder is single box with single cell, and the upstream and downstream girders separate each other. Each pier (i.e., main or transition pier) is consisted of two separated columns with rectangular cross section, and the distance between two pier columns is 17.0 meters. The foundation is a typical elevated pile-cap foundation with the rectangular cap. The oblique steel-tube pile lengths of the main pier are $79 \mathrm{~m}, 80 \mathrm{~m}$, and $85 \mathrm{~m}$, respectively; and the oblique pile lengths of the transition piers are $79 \mathrm{~m}$ and $83 \mathrm{~m}$, respectively. The detailed design about this bridge can be found in the report by Ye et al. [33]. Based on the 5,000 DWT ship finite element model (Figure 2) and the above analyses, both the high-resolution models and the macroelement models using the developed $P$ - $a$ curves and equations are generated as illustrated in Figure 19. In the high-resolution models, the impacted pile caps are modeled by solid elements with constant stress in LS-DYNA. To improve the computational efficiency, beam elements are utilized to model other parts (e.g., pier, girder, and pile) and the lumped mass elements are adopted to model the pile caps except pier number 4 . Two different initial speeds of $2 \mathrm{~m} / \mathrm{s}$ and $4 \mathrm{~m} / \mathrm{s}$ are investigated in this paper, respectively. The former one is approximately equal to the maximum current speed at the bridge site. The latter one is the design impact speed, which is determined based upon the channel 


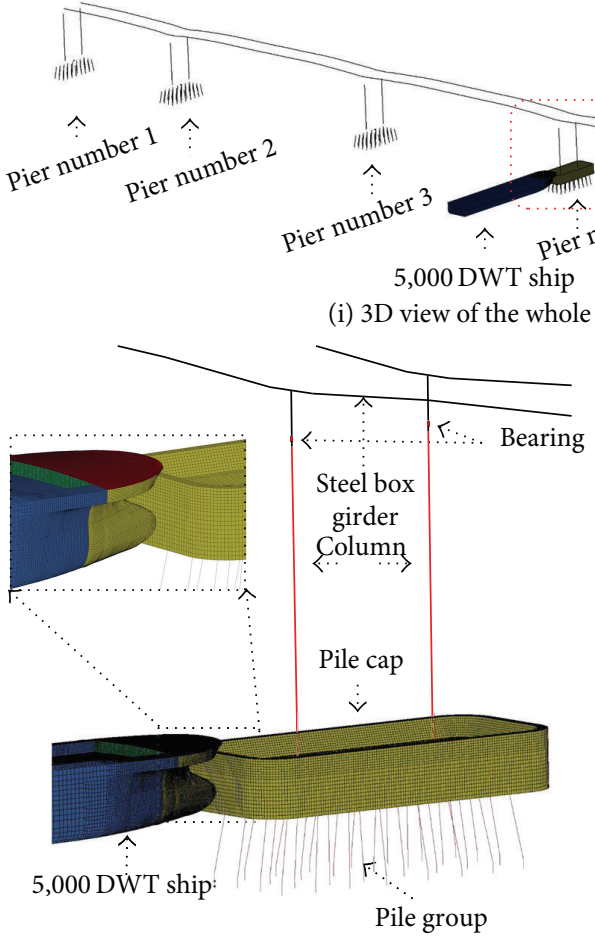

(ii) Finite element model of the impacted pier Steel box girder
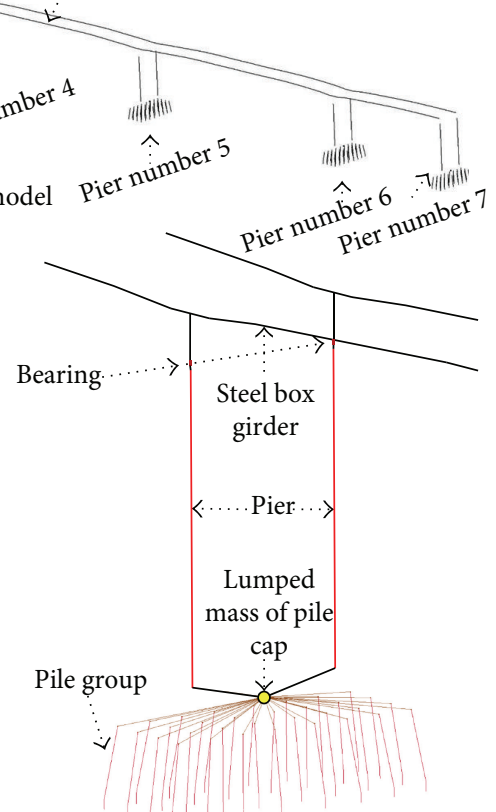

(iii) Finite element model of pier except pier number 4

(a)

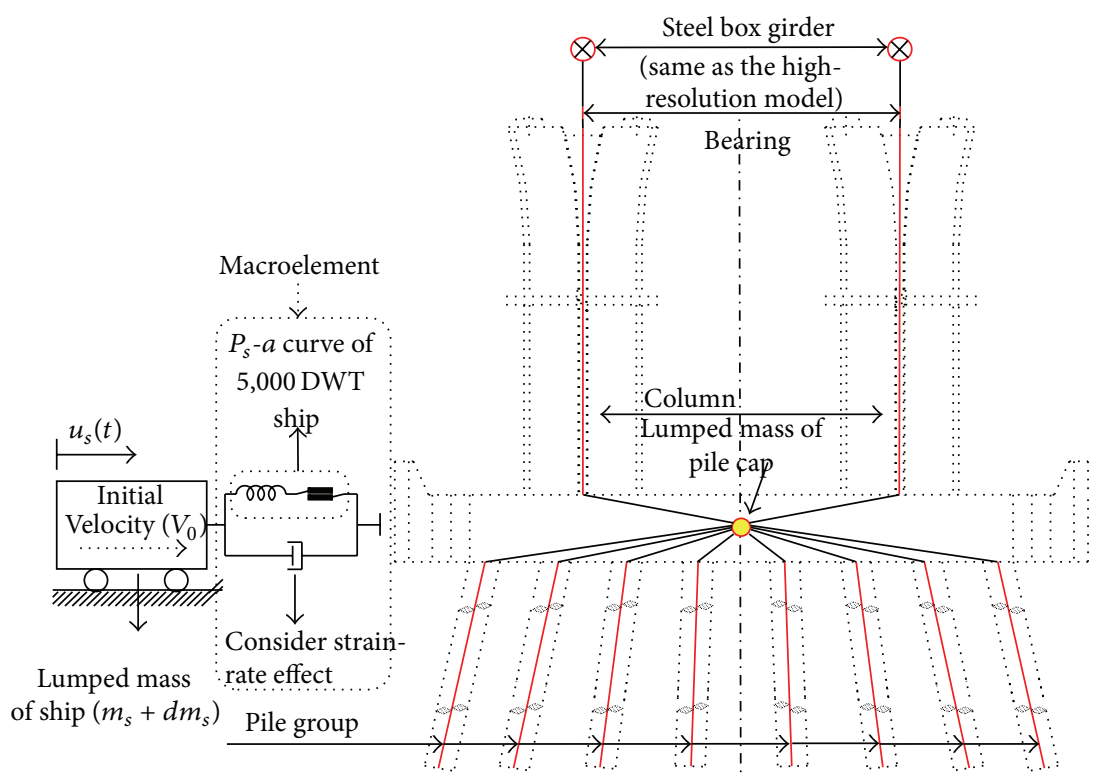

(b)

FIGURE 19: (a) High-resolution model of ship-bridge collision; (b) Macroelement model using the developed $P$ - $a$ curves and equations.

arrangement, typical vessel transit speed, and overall length of the ship using the method in AASHTO [3]. The material parameters are tabulated in Table 4.

In the simplified interaction models (Figure 19(b)), nonlinear macroelements using $P$ - $a$ curves are used to replace the ship models in the high-resolution models (Figure 19(a)), where the parameters are determined by the collision conditions and pile-cap depths. The detailed procedure of the simplified method can be found in the previous researches [15]. To further clarify the necessity of the effect of the pilecap depth, two different approaches are utilized to define the parameters of the macroelement models: (1) using the $P_{w^{-}} a$ 
TABLE 4: Parameters of material models for bridge structures.

\begin{tabular}{lcc}
\hline Component & Young's modulus $(\mathrm{KPa})$ & Density $\left(\mathrm{kg} / \mathrm{m}^{3}\right)$ \\
\hline Girder & $2.1 \times 10^{8}$ & $7.9 \times 10^{3}$ \\
Pier & $3.35 \times 10^{7}$ & $2.6 \times 10^{3}$ \\
Pile cap & $3.15 \times 10^{7}$ & $2.6 \times 10^{3}$ \\
Core concrete & $3.15 \times 10^{7}$ & $2.4 \times 10^{3}$
\end{tabular}

curve without the effect of pile-cap depth; (2) using the $P_{h^{-}} a$ curve based on (12) or (17).

4.2. Results and Discussions. As shown in Figure 20, the dynamic responses of the bridge structure subjected to ship collisions are obtained by means of LS-DYNA and the macroelement model procedures [15].

It is indicated from Figure 20 that both the contact forces and dynamic responses (e.g., displacement and moment) using the $P_{h}-a$ curves are more consistent with those obtained from the high-resolution models through the comparison of the results using $P_{w}-a$ curves without the effect of pile-cap depth. To further evaluate the performances of $P_{w^{-}} a$ and $P_{h^{-}}$ $a$ curves, two evaluating indexes are employed to analyze the results shown in Figure 20: (1) peak response ratio to assess the accuracy of the maximum value (namely, ratio $=$ $Y_{m} / X_{m}$, where $X_{m}$ is the peak response obtained from the high-resolution models; $Y_{m}$ is the peak response from the macroelement models using the $P_{h}-a$ or $P_{w}-a$ curves); (2) Pearson's product-moment correlation coefficient $(r)$, which is a typical measure of the correlation between two variables $X$ and $Y$ [34]. The Pearson's $r$ ranges from -1 to 1 . A value of 1.0 indicates that $X$ and $Y$ have the same trend perfectly. A value of -1.0 is defined when $Y$ decreases as $X$ increases, while a value of 0.0 implies that there is no linear correlation between $X$ and $Y$. In this paper, $X$ and $Y$ are the results from the high-resolution models and the macroelement models, respectively. Based on the results in Figure 20, the above evaluations are conducted and the corresponding results are presented in Figure 21.

As observed in Figure 21(a), although the peak responses using the $P_{w}-a$ curves are larger than the high-resolution analysis results in most of the impact cases, these overestimated results cannot be always guaranteed for all cases (e.g., moment of pier bottom at $4 \mathrm{~m} / \mathrm{s}$ ). The peak responses using the $P_{h}-a$ curves are always in good agreement with the expected values. Furthermore, the peak responses using the $P_{h}-a$ curve are slightly lower than the high-resolution analysis results in some cases. This can be attributed to the fact that the equations (i.e., (12) and (17)) considering the effect of pile-cap depth are developed by the energy ratio $\left(E_{h} / E_{w}\right)$. For the $P_{h^{-}}$ $a$ curves, it is clear that the errors (i.e., the maximal error in Figure 21 (a) is just about $7.0 \%$ ) can be acceptable in practical applications.

Figure 21(b) shows that Pearson's coefficients $(r)$ using the $P_{w}-a$ curve are obviously less than those using $P_{h}-a$ curve, because the characteristic of $P_{h}-a$ curve is different from that of $P_{w}-a$ curve. In addition, there may be a profound phase difference between the time histories of the simplified models using the $P_{w}$-a curve and the high-resolution models (e.g., Pearson's $r$ is -0.54 for the moment of pier bottom at $4 \mathrm{~m} / \mathrm{s}$ ). Based on the above observations, the simplified interaction models and the developed equations are validated by the high-resolution models, and the reasonable $P-a$ curves with the effect of pile-cap depth play a critical role in the demand assessment of bridges subjected to ship collisions.

\section{Conclusions}

In this paper, high-resolution finite element ship models of 5,000 DWT and 10,000 DWT were developed using the general-purpose contact-impact nonlinear finite-element code LS-DYNA. The ship bow crush analyses by rigid walls were conducted to obtain their force-deformation relationships (namely, $P$ - $a$ curves), respectively. The characteristics of the ship bow force-deformation curves were discussed in detail. Generally, the impact forces $(P)$ improve with the increases of bow deformations. This is attributed to the increases of the contact area and the numbers of structural elements in the ship bows. In addition, since each horizontal plate in the ship bows experiences the process from the initial participation to complete failure, the local (temporary) maximum and minimum forces may alternatively occur in the $P$ - $a$ curves.

A large number of ship bow crush simulations were conducted by flat-faced pile-cap impactors of various depths. The effect of pile-cap depth on the $P$ - $a$ curves can be divided into three different phases: Phase I with no reduction, Phase II with the same trend for each pile-cap depth, and Phase III with the variance at various pile-cap depths, respectively. Based on the detailed discussions about the above three phases, the empirical equations were developed using an energy ratio method to account for the effect of pile-cap depth on $P$ - $a$ curves. Finally, a practical example of ship-bridge collisions was calculated to validate the above developed $P$ $a$ curves and equations. The results using the $P-a$ curves with the effect of pile-cap depth are in good agreement with the high-resolution finite element analysis results of shipbridge collisions. In addition, the results using the $P$ - $a$ curves associated with rigid walls may be underestimated in some cases. It is found that the effect of pile-cap depth plays an important role in quantifying ship-impact demand of bridge structures.

\section{Conflict of Interests}

The authors declare that there is no conflict of interests regarding the publication of this paper.

\section{Acknowledgments}

This research is supported by the National Science Foundation of China (Grant nos. 51308202 and 51278376), Hunan Provincial Natural Science Foundation of China (Grant no. 


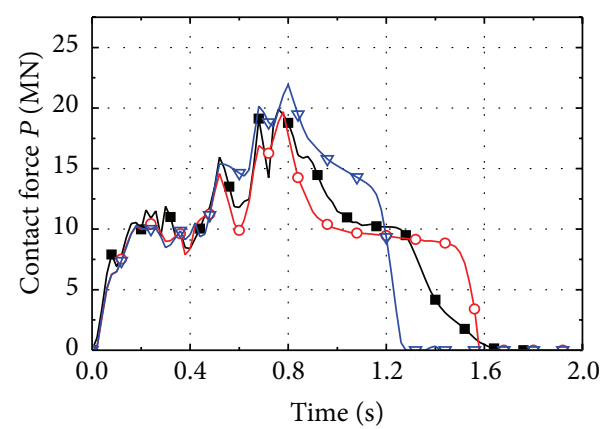

(a)

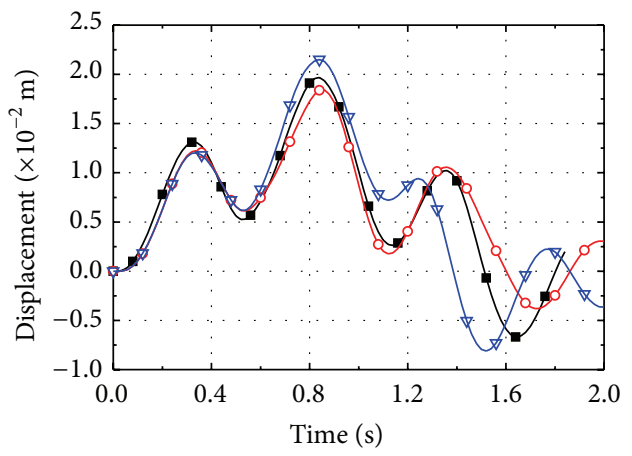

(c)

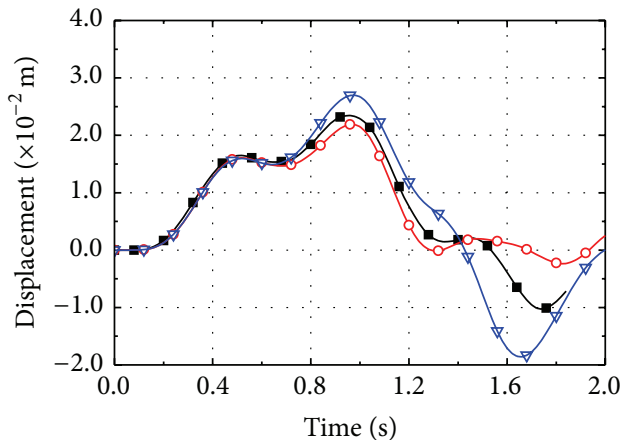

(e)

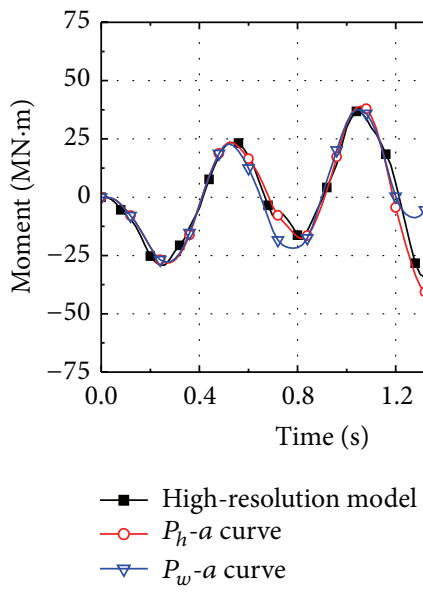

(g)

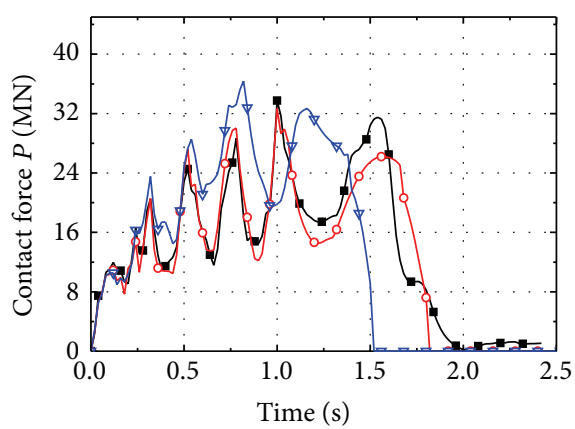

(b)

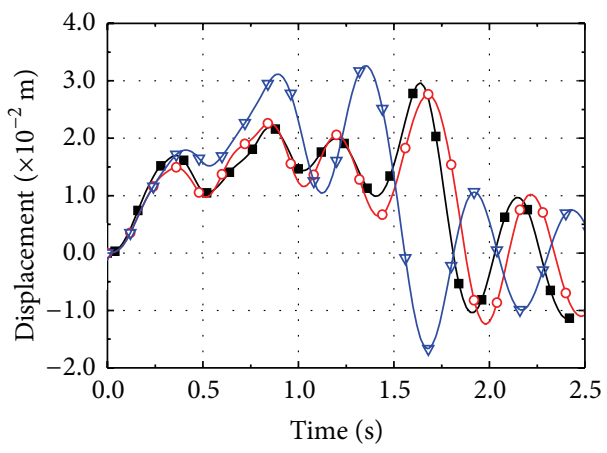

(d)

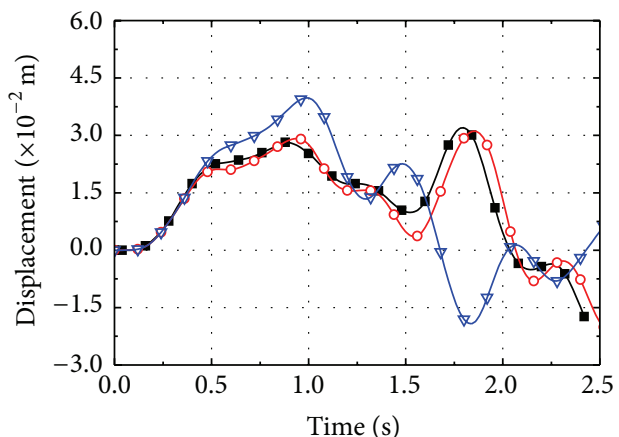

(f)

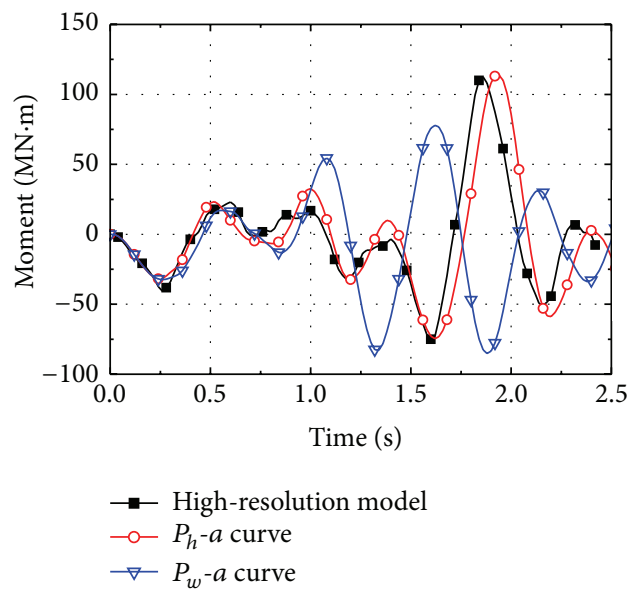

(h)

Figure 20: Comparison of the dynamic responses: (a) contact force $(2 \mathrm{~m} / \mathrm{s})$; (b) contact force $(4 \mathrm{~m} / \mathrm{s})$; (c) displacement of pile cap (2 m/s); (d) displacement of pile cap (4 m/s); (e) displacement of pier top $(2 \mathrm{~m} / \mathrm{s})$; (f) displacement of pier top (4 m/s); (g) moment of pier bottom $(2 \mathrm{~m} / \mathrm{s})$; (h) moment of pier bottom $(4 \mathrm{~m} / \mathrm{s})$. 


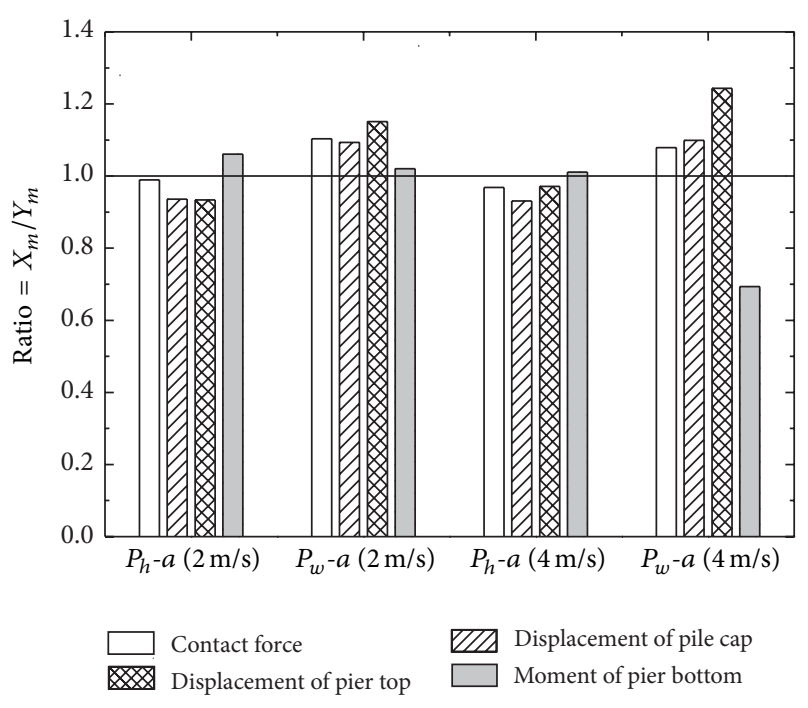

(a)

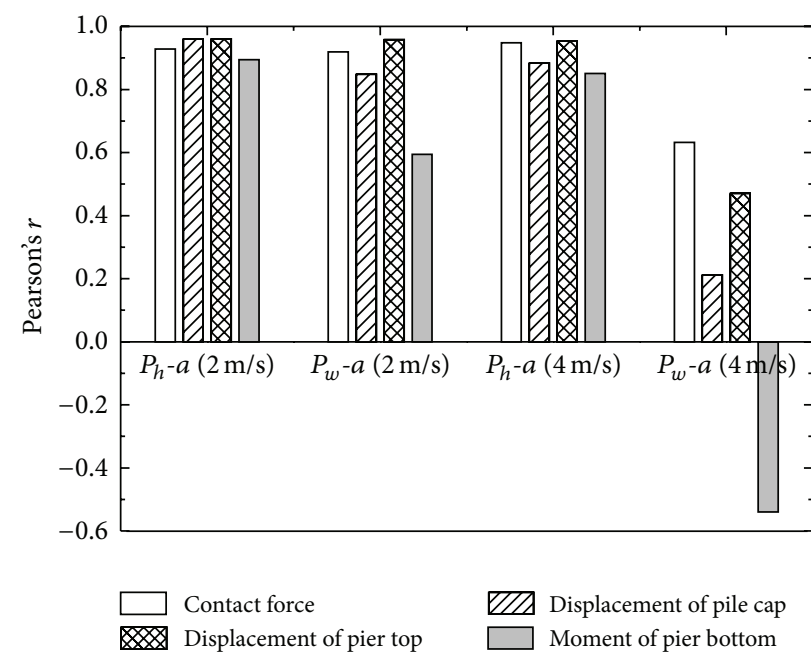

(b)

FIgURE 21: (a) Analysis of peak response; (b) Pearson's correlation with the high-resolution results.

14JJ3056), and the Specialized Research Fund for the Doctoral Program of Higher Education (Grant no. 20130161120026). The authors would like to thank Dr. Yanzhi Liu at Hunan University and Dr. Bo Chen at Central South University in China for their constructive comments and valuable suggestions to improve the quality of the paper.

\section{References}

[1] O. D. Larsen, Ship Collision with Bridges: The Interaction Between Vessel Traffic and Bridge Structures, IABSE, Zürich, Switzerland, 1993.

[2] M. Knott and Z. Prucz, "Vessel collision design of bridges," in Bridge Engineering Handbook, W. F. Chen and L. Duan, Eds., CRC Press, New York, NY, USA, 2000.

[3] AASHTO, Guide Specifications and Commentary for Vessel Collision Design of Highway Bridges, American Association of
State Highway and Transportation Officials, Washington, DC, USA, 2009.

[4] I. Harik, A. Shaaban, H. Gesund, G. Valli, and S. Wang, "United States bridge failures, 1951-1988," Journal of Performance of Constructed Facilities, vol. 4, no. 4, pp. 272-277, 1990.

[5] K. Wardhana and F. C. Hadipriono, "Analysis of recent bridge failures in the United States," Journal of Performance of Constructed Facilities, vol. 17, no. 3, pp. 144-150, 2003.

[6] BSI, Eurocode 1: Actions on Structures-part 1-7: General Actions-Accidental Actions, in: part 1-7: General ActionsAccidental Actions, London, UK, 2006.

[7] P. T. Pedersen, S. Valsgård, D. Olsen, and S. Spangenberg, "Ship impacts: bow collisions," International Journal of Impact Engineering, vol. 13, no. 2, pp. 163-187, 1993.

[8] Ministry of Communications, General Code for Design of Highway Bridges and Culverts (JTG D60-2004), China Communications Press, Beijing, China, 2004.

[9] Ministry of Railways, Fundamental Code for Design on Railway Bridge and Culvert (TB10002. 1-2005), China Railway Publishing House, Beijing, China, 2005.

[10] G. R. Consolazio and D. R. Cowan, "Numerically efficient dynamic analysis of barge collisions with bridge piers," Journal of Structural Engineering, vol. 131, no. 8, pp. 1256-1266, 2005.

[11] M. T. Davidson, G. R. Consolazio, and D. J. Getter, "Dynamic amplification of pier column internal forces due to barge-bridge collision," Transportation Research Record, no. 2172, pp. 11-22, 2010.

[12] W. Fan and W. C. Yuan, "Shock spectrum analysis method for dynamic demand of bridge structures subjected to barge collisions," Computers and Structures, vol. 90-91, no. 1, pp. 1-12, 2012.

[13] D. J. Getter, G. R. Consolazio, and M. T. Davidson, "Equivalent static analysis method for barge impact-resistant bridge design," Journal of Bridge Engineering, vol. 16, no. 6, pp. 718-727, 2011.

[14] P. Yuan and I. E. Harik, "One-dimensional model for multibarge flotillas impacting bridge piers," Computer-Aided Civil and Infrastructure Engineering, vol. 23, no. 6, pp. 437-447, 2008.

[15] W. Fan, W. C. Yuan, Z. Yang, and Q. W. Fan, "Dynamic demand of bridge structure subjected to vessel impact using simplified interaction model," Journal of Bridge Engineering, vol. 16, no. 1, pp. 117-126, 2011.

[16] W. Fan, Dynamic demand of bridge structures and capacity of pile-supported protection structures under vessel impacts [Ph.D. thesis], Tongji University, Shanghai, China, 2012 (Chinese).

[17] K. E. Meier-Dörnberg, Ship Collisions, Safety Zones, and Loading Assumptions For Structures in Inland Waterways, Verein Deutscher Ingenieure (Association of German Engineers), Duesseldorf, Germany, 1983.

[18] G. R. Consolazio and D. R. Cowan, "Nonlinear analysis of barge crush behavior and its relationship to impact resistant bridge design," Computers and Structures, vol. 81, no. 8-11, pp. 547-557, 2003.

[19] Y. Sha and H. Hao, "Laboratory tests and numerical simulations of barge impact on circular reinforced concrete piers," Engineering Structures, vol. 46, pp. 593-605, 2013.

[20] P. Yuan, Modeling, simulation and analysis of multi-barge flotillas impacting bridge piers [Ph.D. thesis], University of Kentucky, Lexington, Ky, USA, 2005.

[21] G. R. Consolazio, M. T. Davidson, and D. R. Cowan, "Barge bow force-deformation relationships for barge-bridge collision analysis," Transportation Research Record, no. 2131, pp. 3-14, 2009. 
[22] LSTC, LS-DYNA keyword user's manual Version 971, Livermore Software Technology Corporation, 2009.

[23] H. Endo, Y. Yamada, O. Kitamura, and K. Suzuki, "Model test on the collapse strength of the buffer bow structures," Marine Structures, vol. 15, no. 4-5, pp. 365-381, 2002.

[24] Y. Yamada, H. Endo, H. Kawano, and M. Hirakata, "Collapse mechanism of the buffer bow structure on axial crushing," in Proceedings of the 13th International Offshore and Polar Engineering Conference, J. S. Chung, J. Wardenier, R. M. W. Frederking, and W. Koterayama, Eds., pp. 534-541, Honolulu, Hawaii, USA, May 2003.

[25] Shanghai Ship and Shipping Research Institute, "Vessel impact forces and anti-collision measures of the 4th Nanjing Bridge," Report of Shanghai Ship and Shipping Research Institute, Shanghai, China, 2005.

[26] Y. Sha and H. Hao, "Nonlinear finite element analysis of barge collision with a single bridge pier," Engineering Structures, vol. 41, pp. 63-76, 2012.

[27] Y. Shi, H. Hao, and Z. X. Li, "Numerical derivation of pressureimpulse diagrams for prediction of RC column damage to blast loads," International Journal of Impact Engineering, vol. 35, no. 11, pp. 1213-1227, 2008.

[28] W. Fan, W. C. Yuan, and M. Zhou, "A nonlinear dynamic macro-element for demand assessment of bridge substructures subjected to ship collision," Journal of Zhejiang University: Science A, vol. 12, no. 11, pp. 826-836, 2011.

[29] H. S. Alsos and J. Amdahl, "On the resistance of tanker bottom structures during stranding," Marine Structures, vol. 20, no. 4, pp. 218-237, 2007.

[30] R. Tornqvist and B. C. Simonsen, "Safety and structural crashworthiness of ship structures, modelling tools and application in Design," in Proceedings of the International Conference on Collision and Grounding of Ships (ICCGS '04), Izu, Japan, 2004.

[31] H. Svensson, "Protection of bridge piers against ship collision," Steel Construction, vol. 2, pp. 21-32, 2009.

[32] Y. Yamada and H. Endo, "Experimental and numerical study on the collapse strength of the bulbous bow structure in oblique collision," Marine Technology, vol. 45, no. 1, pp. 42-53, 2008.

[33] A. J. Ye, M. Ren, J. Jin, P. C. yin, and Z. Y. Su, "Seismic performance of Chongqi Bridge connecting Chongming to Qidong over Yangtze River," Report of State Key Laboratory of Disaster Reduction in Civil Engineering, Tongji University (in Chinese), 2008.

[34] E. S. Pearson and H. O. Hartley, Biometrika Tables for Statisticians, vol. 1, Cambridge University Press, New York, NY, USA, 2nd edition, 1959. 

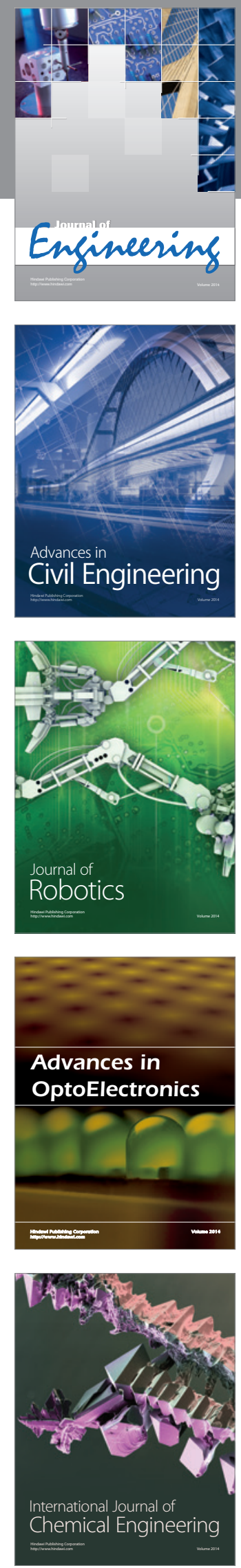

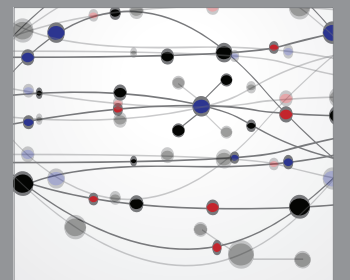

The Scientific World Journal
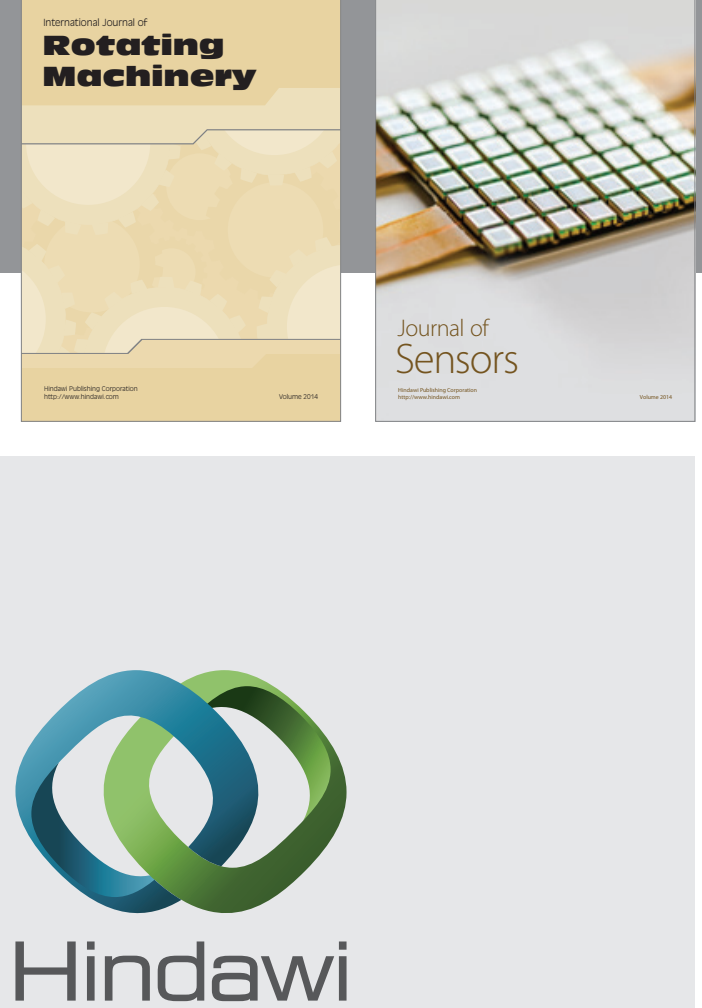

Submit your manuscripts at http://www.hindawi.com
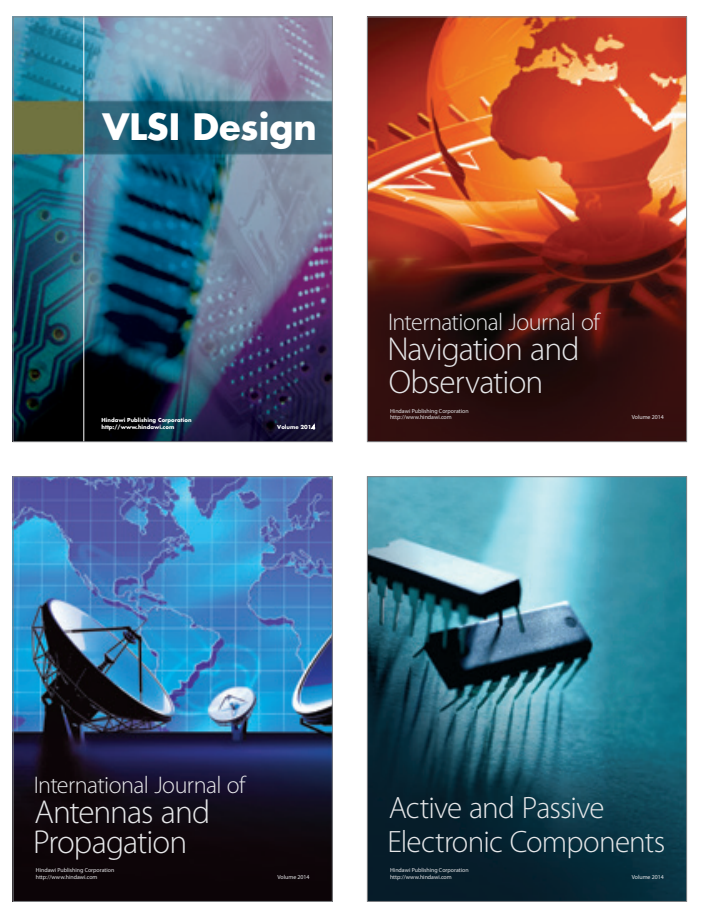
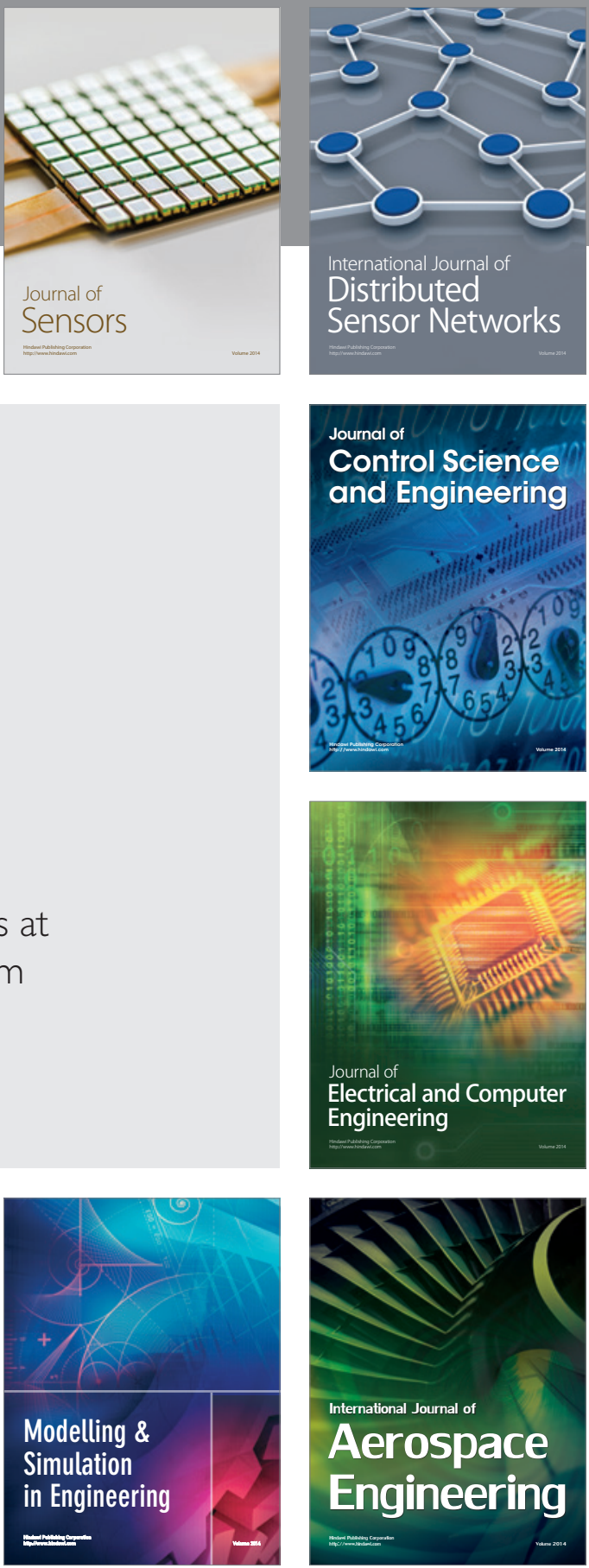

Journal of

Control Science

and Engineering
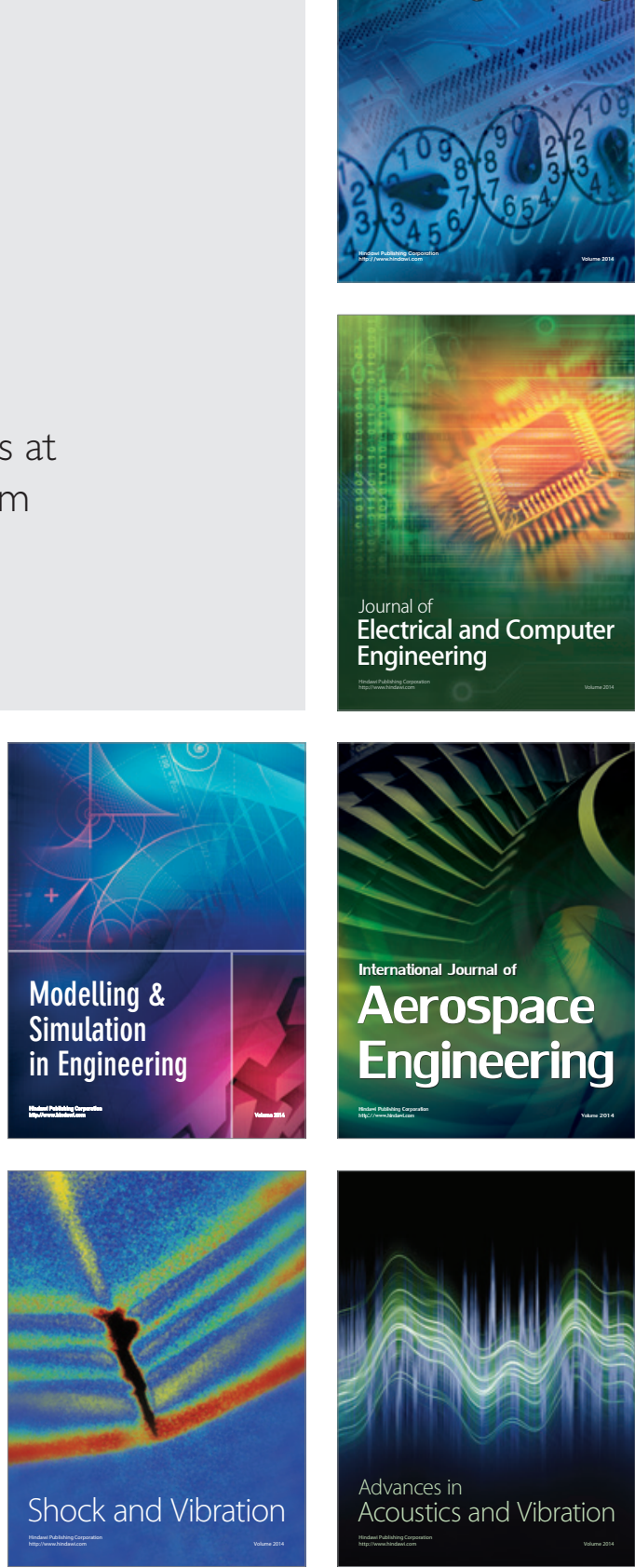